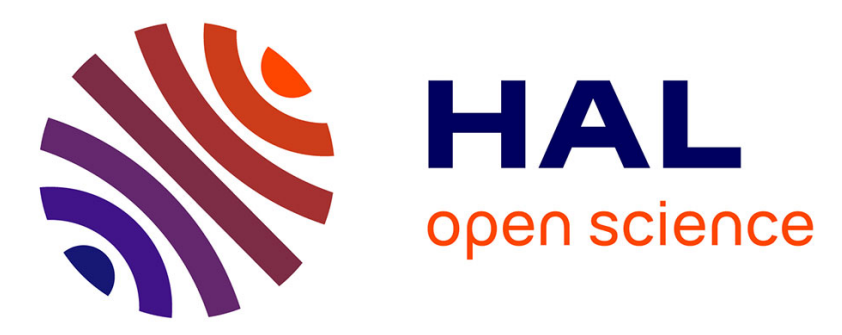

\title{
Dewetting Temperatures of Prefrozen and Grafted Layers in Solid Ultrathin Films Viewed as Melt-Memory Effects
}

Robert F Tournier, Michael I Ojovan

\section{- To cite this version: \\ Robert F Tournier, Michael I Ojovan. Dewetting Temperatures of Prefrozen and Grafted Layers in Solid Ultrathin Films Viewed as Melt-Memory Effects. Physica B: Condensed Matter, 2021, 611, pp.412796. 10.1016/j.physb.2020.412796 . hal-02961002v5}

\section{HAL Id: hal-02961002 \\ https://hal.science/hal-02961002v5}

Submitted on 6 Feb 2021

HAL is a multi-disciplinary open access archive for the deposit and dissemination of scientific research documents, whether they are published or not. The documents may come from teaching and research institutions in France or abroad, or from public or private research centers.
L'archive ouverte pluridisciplinaire HAL, est destinée au dépôt et à la diffusion de documents scientifiques de niveau recherche, publiés ou non, émanant des établissements d'enseignement et de recherche français ou étrangers, des laboratoires publics ou privés. 


\title{
Dewetting Temperatures of Prefrozen and Grafted Layers in Solid Ultrathin Films Viewed as Melt-Memory Effects
}

\author{
Robert F. Tournier ${ }^{(1)}$, Michael I. Ojovan $*(2,3)$ \\ (1) Univ. Grenoble Alpes, CNRS, Grenoble INP*, L.N.C.M.I., 38000 Grenoble, \\ France, *Institute of Engineering Univ. Grenoble Alpes: \\ robert.tournier@lncmi.cnrs.fr \\ (2) Department of Materials, Imperial College London, London SW7 2AZ, United \\ Kingdom:m.ojovan@imperial.ac.uk \\ (3) Institute of Geology of Ore Deposits, Petrography, Mineralogy and Geochemistry, \\ 119017 Moscow, Russia:m.i.ojovan@gmail.com \\ *correspondance: $\underline{\text { m.i.ojovan@gmail.com }}$
}

\begin{abstract}
Undercooled phase exists behind glass phase with superheated medium-range order between $T_{g}$ and $T_{n+}>T_{m}$. The ordered volume fraction stays equal to the percolation threshold $\mathrm{F} \cong 0.15$ of broken bonds up to $\mathrm{T}_{\mathrm{n}+}$. The difference $\Delta \mathrm{T}_{\mathrm{g}}$ between $\mathrm{T}_{\mathrm{g}}$ (bulk) of films with thickness $\left(h>h_{0}\right)$ and $\mathrm{T}_{\mathrm{g}}(\mathrm{h})$ of ultrathin films of thickness $\left(\mathrm{h}<\mathrm{h}_{0}\right)$ is a linear function of $\left(\mathrm{h}-\mathrm{h}_{\mathrm{o}}\right)$. Dense layer with minimum thickness $h_{r}$ is grafted against substrate by isothermal annealing, rinsed to reduce film thickness below $h_{r} / F$, and finally dewetted at $T_{g}$. Similar thickness prepared and annealed near $T_{m}$ and heated above $T_{m}$ contains residual crystallized layer dewetting at $T_{n+}$. The prefrozen layer reproduces the glassy grafted layer in a crystallized state up to $\mathrm{T}_{\mathrm{n}+}$. Melting heat and melting temperature $T_{m}$ are linear functions of $h$ for $h<h_{0}$. Prefrozen layers are due to meltmemories leading to new scenarios of crystallization.
\end{abstract}

Keywords: melt-memory, glass phase, prefreezing, grafted polymers, undercooling, superheating, percolation threshold.

\section{Introduction}

The development of nanoscale devices increases the need of stable ultrathin films. Recent works shows the formation of residual films of polymers with uniform surfaces and thicknesses below $7 \mathrm{~nm}$ after submitting thicker films to various solvent rinsing [1-3]. This is important for many applications in nanoelectronics [4,5], biomedical [6], tissue engineering [7], coatings [8] but also for fundamental research. These ultrathin films are stable up to a dewetting temperature $\mathrm{T}_{\mathrm{w}}$ where they are transformed in liquid polymer islands below the melting temperature $\mathrm{T}_{\mathrm{m}}$ of polymer.

The glass transition temperature of any film depends on the substrate nature, the polymer thickness $h$ and the annealing temperature used to graft the film before rinsing [3]. The temperature $\mathrm{T}_{\mathrm{g}}$ (bulk) is decreased from its value in bulk materials for film thicknesses $\mathrm{h}$ smaller than $\mathrm{h}_{0}$, the thickness limit $\mathrm{h}_{0}$ being of the order of several tenths of nanometers depending on substrate and polymer natures [4,9,10]. A linear relation given in (1) between $h$ and the temperature $\mathrm{T}_{\mathrm{g}}(\mathrm{h})$ is observed for $\mathrm{h}<\mathrm{h}_{0}$ leading to the conclusion that a simple theoretical picture is possible to describe these phenomena [11]:

$T_{g}(\mathrm{~h})=T_{g}($ bulk $) \times\left[1-\frac{\left(h_{0}-h\right)}{d}\right]$. 
where $\mathrm{d}$ is a correlation length quantifying the influence of free surface or substrate; for free surfaces of polystyrene, $\mathrm{h}_{0}=69$ and $\mathrm{d}=213 \mathrm{~nm}$ [11]. For polystyrene deposited on silicon oxide and annealed at $130^{\circ} \mathrm{C}, \mathrm{h}_{0}=67$ and $\mathrm{d}=97 \mathrm{~nm}[10]$.

The average adsorbed layer thickness of polystyrene depends on the temperature of grafting and varies from $1.4 \mathrm{~nm}$ without annealing films deposited on silica to $5.2 \mathrm{~nm}$ after 7 hours at $\mathrm{T}_{\mathrm{a}}=423 \mathrm{~K}\left(150^{\circ} \mathrm{C}\right)$ [9]. A 24-hour annealing at $\mathrm{T}_{\mathrm{a}}=433 \mathrm{~K}\left(160^{\circ} \mathrm{C}\right)$ of films deposited on silicon also increases the average residual thickness from 2 to $5.2 \mathrm{~nm}$ [3].

In parallel to these studies, the formation of crystallized layers of polyethylene above $\mathrm{T}_{\mathrm{m}}=108{ }^{\circ} \mathrm{C}$ has been observed. Here, the substrate influence induces a first-order transition giving rise to a wetting temperature $T_{\mathrm{w}}>\mathrm{T}_{\mathrm{m}}$ by cooling and a dewetting by heating the films at the same temperature. The film thickness of polyethylene varies from 1.5 to $2.7 \mathrm{~nm}$ using substrates of $\mathrm{MoS}_{2}$ and HOPG (highly oriented pyrolytic graphite) respectively. Here, the influence of substrate is apparently important. In fact, the temperature was raised during $30 \mathrm{mn}$ to $\mathrm{T}_{\mathrm{a}}=160^{\circ} \mathrm{C}$ for thin films deposited on $\mathrm{MoS}_{2}$ and $\mathrm{T}_{\mathrm{a}}=150^{\circ} \mathrm{C}$ for thin films deposited on HOPG and then slowly cooled to room temperature. The influence of the annealing temperature $\mathrm{T}_{\mathrm{a}}$ and of all thermal history is more important than the nature of the substrate because $\mathrm{T}_{\mathrm{w}}$ varies from $155{ }^{\circ} \mathrm{C}$ with $\mathrm{T}_{\mathrm{a}}=160{ }^{\circ} \mathrm{C}$ to $124{ }^{\circ} \mathrm{C}$ with $\mathrm{T}_{\mathrm{a}}=150{ }^{\circ} \mathrm{C}[12,13]$. The annealing at $\mathrm{T}_{\mathrm{a}}=150$ ${ }^{\circ} \mathrm{C}$ has lowered the wetting temperature while that at $\mathrm{T}_{\mathrm{a}}=160{ }^{\circ} \mathrm{C}$ is not changed because of the first order transition at $\mathrm{T}_{\mathrm{w}}=155^{\circ} \mathrm{C}$. These recent results have to be compared with the previous finding that the prefrozen layer persists, at least up to $150{ }^{\circ} \mathrm{C}$, after 24 hours of annealing at $\mathrm{T}_{\mathrm{a}}$ $=150^{\circ} \mathrm{C}$, followed by quenching to room temperature [13].

The interface-induced crystallization of polycaprolactone on graphite via first- order prewetting of the crystalline phase has been observed at $82{ }^{\circ} \mathrm{C}$ with $\mathrm{T}_{\mathrm{m}}=62{ }^{\circ} \mathrm{C}$ after $30 \mathrm{mn}$ of annealing at $85{ }^{\circ} \mathrm{C}$ followed by a slow cooling. The prefrozen layer has a thickness of $4.3 \mathrm{~nm}$ at the dewetting temperature of $82{ }^{\circ} \mathrm{C}$ with a thickness increase up to $13 \mathrm{~nm}$ at $64{ }^{\circ} \mathrm{C}$, thickness now equal to that of the initial film [14].

An interface of a solid material can initiate crystallization in liquids by heterogeneous nucleation or prefreezing [15-18]. The formation of prefrozen layer through a first-order transition is viewed as being due to the interfacial energy difference between that of substratemelt and those of substrate-crystal and crystal-melt favorizing crystallization [19]. Nevertheless, the calculated value of $\mathrm{h}_{0}=1.17 \mathrm{~nm}$ deduced from this model for polyethylene [12] is too low when compared to experimental values of $69 \mathrm{~nm}$ observed for polystyrene $[10,11]$. An absence of tiny crystals in the melt above $T_{m}$ is always assumed because the classical nucleation equation has fixed this rule which is not respected by melts [20,21]. The prefrozen layer is due to the presence of surviving crystals having radius smaller than the critical one assembled on the substrate to reduce their surface energy. This phenomenon of dewetting is due to the melting of the prefrozen layer leading to an unstable liquid film above $T_{\mathrm{w}}$. Consequently, the linear law (1) with high d values exists instead of an exponential law used to predict the stability of liquid thin films [19-22]. It is the purpose of this paper to present this alternative.

\section{2- New approaches}

The glass transition is not always viewed as a freezing phenomenon in the potential energy landscape. Two other approaches exist: 1- The liquid-to-glass transition results from percolation phenomenon of atom groups formed above $T_{g}$ during cooling [23-25]. A deep thermodynamic transition from the glass toward liquid state results from the percolation of broken bonds (configurons) between atoms [26-28]; 2- Two liquids 1 and 2 give rise after the first cooling, to an intermediate Phase 3 below $\mathrm{T}_{3}<\mathrm{T}_{\mathrm{g}}$ respecting the entropy constraints [29- 
31]. The negative activation energy shows that Phase 3 is hidden behind the glassy phase acting as an intermediate invasive phase during the second cooling [32].

Following Angell ideas of configurons in covalently-bonded materials [33] extended to metallic systems via Egami's approach on bonds [34,35], it is assumed that the system of bonds has two states, namely, the ground state corresponding to unbroken bonds and the excited state corresponding to broken bonds. It has been described by the statistics of two-level systems separated by the energy interval $\mathrm{G}_{\mathrm{d}}$. The two approaches converge because the Gibbs free energy of Phase 3 is equal to $G_{d}$. Phase 3 is, in fact, the configuron phase which survives above $\mathrm{T}_{\mathrm{m}}$ in a liquid with medium -range order up to a temperature $\mathrm{T}_{\mathrm{n}+\text {. }}$ The transition temperatures $T_{g}$ and $T_{n+}$ accompanied by enthalpy or entropy changes of Phase 3 are predicted in many cases: annealing above and below $\mathrm{T}_{\mathrm{g}}$, vapor deposition, formation of glacial and quasi-crystalline phases in perfect agreement with experiments. Any transformation of Phase 3 changes the initial liquid enthalpy and rejuvenation at $\mathrm{T}_{\mathrm{g}}<\mathrm{T}<\mathrm{T}_{\mathrm{n}+}$ does not lead to the enthalpy of the initial liquid [32].

At high heating rates, the volume fraction of Phase 3 associated with medium-range order remains equal to the percolation threshold $\mathrm{F}=0.15 \pm 0.01$ up to $\mathrm{T}_{\mathrm{n}+}$ when crystallization does not occur. There is no more medium-range order above $T_{n+}$. The transition at $T_{n+}$ produces an exothermic latent heat and the liquid is now ready for high undercooling rates.

At low heating rates, crystallization occurs at $\mathrm{T}_{\mathrm{x}}<\mathrm{T}_{\mathrm{m}}$ followed by melting at $\mathrm{T}_{\mathrm{m}}$. The crystallized phase still contains either $15 \%$ of melt or give rise to $15 \%$ of tiny and surviving crystals. Depending on these two assumptions, the latent heat at $\mathrm{T}_{\mathrm{n}+}$ would be endothermic for the case of the presence of tiny crystals in the melt or exothermic at $T_{n+}$ for the case of residual liquid droplets of ordered Phase 3. Two experiments show that the latent heat at $T_{n+}$ is endothermic. The melting of Phase 3 in $\mathrm{Zr}_{41.2} \mathrm{Ti}_{19.8} \mathrm{Cu}_{12.5} \mathrm{Ni}_{10} \mathrm{Be}_{22.5}$ is observed by measuring the FWHM of the first peak of $S(Q)$ and the endothermic latent heat at the same temperature [36]. This event occurs at $\mathrm{T}_{\mathrm{n}+}=1116 \mathrm{~K}$ [30]. An undercooling of $220 \mathrm{~K}$ observed for CoB eutectic liquid is followed by crystallization and melting at $\mathrm{T}_{\mathrm{m}}=1406 \mathrm{~K}$ [37]. An endothermic heat is still observed at $1656 \mathrm{~K}$ corresponding to the melting of a small fraction of surviving tiny crystals. In this example, the liquid has not been cooled below its glass transition because the cooling rate is too weak. Only a small fraction of surviving crystals far below $15 \%$ is formed during supercooling.

The surviving crystal fraction is equal to $F$ between $T_{m}$ and $T_{n+}$ when Phase 3 has been formed below $\mathrm{T}_{3}$ and is crystallized after slow heating. A second melting temperature called $\mathrm{T}_{\mathrm{n}+}$ exists in these conditions [29-31,38]. In this case, crystallization occurs at $T_{m}$ when cooling starts from $T_{m}<T<T_{n+}$ and is the result of percolation of surviving crystals at $T_{m}$. In the absence of Phase 3, cooling from $\mathrm{T}>\mathrm{T}_{\mathrm{n}+}$ leads to crystallization after a deep undercooling. There is a need of new experiments devoted to crystallization by taking the existence of Phase 3 into account up to the temperature $\mathrm{T}_{\mathrm{n}+}$.

Melting and "crystallization" of polymers exhibit reversible features which could be related to Phase 3 [39]. An abundant literature is devoted to the observation of two melting temperatures of crystallized polymers. An example of this phenomenon leads to the melting of phase 3 in semicrystalline polyimide based on 1,3-bis (4-aminophenoxy) benzene (TPER) and 3,3', 4,4'-benzophenonetetracarboxylic dianhydride (BTDA). There is no crystallization of the bulk liquid and only that of phase 3 , starting with $\mathrm{T}_{\mathrm{g}}=224{ }^{\circ} \mathrm{C}$, crystallizing at $347{ }^{\circ} \mathrm{C}$ and melting at $\mathrm{T}_{\mathrm{n}+}=394.5^{\circ} \mathrm{C}$ [40, Figure 8.5a]. The exothermic and endothermic latent heats are equal as expected.

A theory of melt-memory in polymer crystallization refers to details of crystallization processes at the crystallization temperature from a melt kept initially at the melt temperature $\mathrm{T}_{\mathrm{m}}$ which deeply depend on the nature of initial melt state and accompanied by memory effects. An intermediate inhomogeneous melt state is already invoked in the pathway between 
the melt and crystalline states [41]. Phase 3 with its volume fraction $F \cong 0.15$ is this intermediate phase which remains crystallized up to $\mathrm{T}_{\mathrm{n}+}$.

\section{3- Application of new approaches to polymer thin films}

\section{3-1 Equations}

The main observed phenomenon is the dependence of the glass transition temperature $T_{g}$ with the thickness $h$ and the grafting temperature $T_{a}$. The heat capacity jump is equal to $1.5 \times \mathrm{H}_{\mathrm{m}} / \mathrm{T}_{\mathrm{m}}$ in polymers as shown in 1960 by Wunderlich [42] and confirmed for many molecular glasses [43] (where $\mathrm{H}_{\mathrm{m}} / \mathrm{T}_{\mathrm{m}}=\mathrm{S}_{\mathrm{m}}$ is the crystal melting entropy).

The latent heat coefficient $\Delta \varepsilon$ associated with a transition at $\mathrm{T} \neq \mathrm{T}_{\mathrm{g}}$ is calculated using the following equations (2-5) predicting two reduced homogeneous nucleation temperatures of fragile Liquid 2 resulting from the completed classical nucleation equation [29,31]:

$$
\theta_{n^{-}}=\left(-3 \pm\left[9-4\left(2-\varepsilon_{g s 0}-\Delta \varepsilon\right) \varepsilon_{g s 0} / \theta_{0 g}^{2}\right]^{0.5}\right) \theta_{0 g}^{2} / 2 \varepsilon_{g s 0}
$$

where $\varepsilon_{g s}(\theta)=\varepsilon_{g s 0}\left(1-\theta^{2} \times \theta_{0 g}^{-2}\right)+\Delta \varepsilon$

$\varepsilon_{g s}(\theta=0)=\varepsilon_{g s 0}=1.5 \theta_{2}+2=1.5 \theta_{g}+2$,

$\theta_{0 g}^{2}=\frac{8}{9} \varepsilon_{g s 0}-\frac{4}{9} \varepsilon_{g s 0}^{2}$

where $\theta=\left(\mathrm{T}-\mathrm{T}_{\mathrm{m}}\right) / \mathrm{T}_{\mathrm{m}}$.

For a latent heat coefficient $\Delta \varepsilon=0, \theta_{\mathrm{n}-}=\theta_{\mathrm{g}}=\left(\mathrm{T}_{\mathrm{g}}-\mathrm{T}_{\mathrm{m}}\right) / \mathrm{T}_{\mathrm{m}}$ while there are two homogeneous nucleation

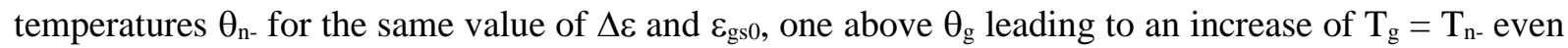
to glacial phase transitions for high values of $\Delta \varepsilon$ and a decrease symmetrical from the first one with regard to $T_{\mathrm{g}}$ [31]. The equation (2) can also be applied with an increased or a decreased value of $\varepsilon_{\mathrm{gs} 0}$, leading to changes of $\theta_{\mathrm{g}}$ and $\theta_{0 \mathrm{~g}}{ }^{2}$.

The heat capacity jump of $1.5 \times \mathrm{S}_{\mathrm{m}}$ is predicted for many liquids [44] having an enthalpy coefficient $\varepsilon_{\mathrm{ls}}(\theta)$ for fragile Liquid 1 respecting (6-8) and $\mathrm{a}=1$ :

$$
\begin{aligned}
& \varepsilon_{l s}(\theta)=\varepsilon_{l s 0}\left(1-\theta^{2} \times \theta_{0 m}^{-2}\right), \\
& \varepsilon_{l s}(\theta=0)=\varepsilon_{l s 0}=1.5 \theta_{1}+2=a \theta_{g}+2, \\
& \theta_{0 m}^{2}=\frac{8}{9} \varepsilon_{l s 0}-\frac{4}{9} \varepsilon_{l s 0}^{2} .
\end{aligned}
$$

The enthalpy value is obtained by multiplying the enthalpy coefficient by the melting heat $\mathrm{H}_{\mathrm{m}}$. The enthalpy coefficient $\Delta \varepsilon_{\mathrm{lg}}$ of Phase 3 obeys (9):

$$
\Delta \varepsilon_{\lg (\theta)}=\varepsilon_{l s}-\varepsilon_{g s}=\varepsilon_{l s 0}-\varepsilon_{g s 0}+\Delta \varepsilon-\theta^{2}\left(\varepsilon_{l s 0} / \theta_{0 m}^{2}-\varepsilon_{g s 0} / \theta_{0 g}^{2}\right)
$$

\section{3-2 Application to polyethylene}


The glass transition temperature of polyethylene is $\mathrm{T}_{\mathrm{g}}=256 \mathrm{~K}$ and the melting temperature $\mathrm{T}_{\mathrm{m}}=381 \mathrm{~K}[45,46]$. The enthalpy coefficients $\varepsilon_{\mathrm{ls}}$ of Liquid 1 , $\varepsilon_{\mathrm{gs}}$ of Liquid 2, and $\Delta \varepsilon_{\lg }$ of Liquid 3 are determined using (4-9) and given in (10-12) for bulk films.

$$
\begin{aligned}
& \varepsilon_{l s}(\theta)=1.67192\left(1-4.1019 \times \theta^{2}\right), \\
& \varepsilon_{g s}(\theta)=1.50787\left(1-3.0321 \times \theta^{2}\right), \\
& \Delta \varepsilon_{\lg (\theta)}=0.16404-2.286 \times \theta^{2}
\end{aligned}
$$

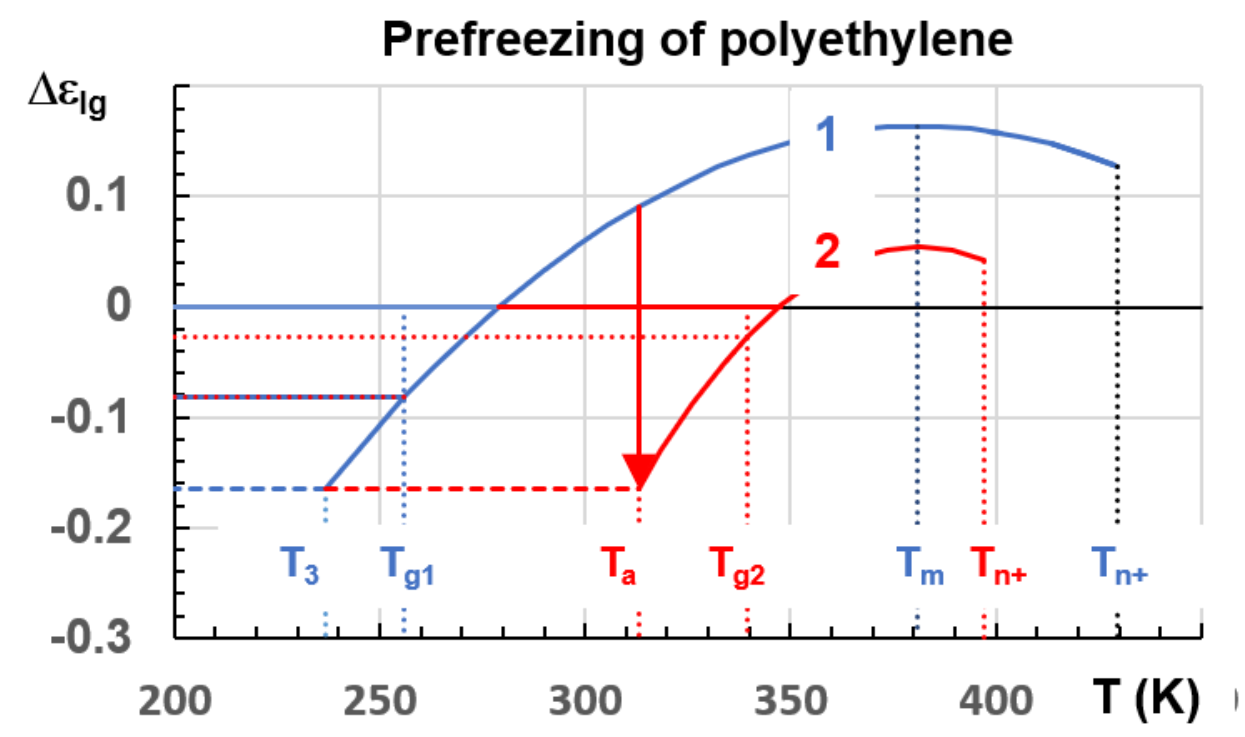

Figure 1: Enthalpy coefficients of bulk polyethylene (1) and annealed at $T_{a}=313 \mathrm{~K}(2): T_{3}=$ $236.7 \mathrm{~K}, \quad T_{g 1}=256 \mathrm{~K}, T_{a}=313 \mathrm{~K}\left(39.9^{\circ} \mathrm{C}\right), T_{g 2}=339.4 \mathrm{~K}, T_{m}=381 \mathrm{~K}$, and prefreezing temperatures $T_{n+}(2)=397.1 \mathrm{~K}\left(124{ }^{\circ} \mathrm{C}\right), T_{n+}(1)=429.4 \mathrm{~K}\left(156.3{ }^{\circ} \mathrm{C}\right)$. Phase 3 enthalpy coefficient equal to $-\Delta \varepsilon_{\lg 0}=-0.16404$ below $T_{a}$.

The enthalpy coefficient $\Delta \varepsilon_{\mathrm{lg}}$ is represented in Figure 1 on Line 1 with $\mathrm{T}_{\mathrm{g} 1}=256 \mathrm{~K}$. Phase 3 is formed at $T_{3}=236.7 \mathrm{~K}$ with an enthalpy coefficient equal to $-\Delta \varepsilon_{\lg 0}=-0.16404$ in (12). This phase survives above $T_{m}$ up to the homogeneous nucleation temperature $T_{n+}=429.4$ $\mathrm{K}\left(156.3^{\circ} \mathrm{C}\right)$, obeying (13) and (9):

$\theta_{n+}=\Delta \varepsilon_{l g}\left(\theta_{n+}\right)$

This value of $\mathrm{T}_{\mathrm{n}+}$ is equal to the dewetting temperature $\mathrm{T}_{\mathrm{w} 1}=155^{\circ} \mathrm{C}$ measured by Tariq et al [12].

Such film is grafted at $\mathrm{T}_{\mathrm{a}}=313 \mathrm{~K}$ during $30 \mathrm{mn}$ leading to a new enthalpy coefficient $\Delta \varepsilon_{\mathrm{lg}}=-0.16404$ equal to that of initial Phase 3 at $\mathrm{T}_{\mathrm{a}}$ represented along Line 2 in Figure 1 with $\theta_{\mathrm{g} 2}=-0.10928\left(\mathrm{~T}_{\mathrm{g} 2}=339.4 \mathrm{~K}\right)$. The enthalpy coefficients of new liquids grafted at $\mathrm{T}_{\mathrm{a}}=313 \mathrm{~K}$ calculated using (4-9) are:

$\varepsilon_{l s}(\theta)=1.89072\left(1-10.89 \times \theta^{2}\right)$, 
$\epsilon_{g s}(\theta)=1.83608\left(1-7.4761 \times \theta^{2}\right)$,

$\Delta \epsilon_{\lg (\theta)}=0.054638-6.8632 \times \theta^{2}$.

The enthalpy coefficient of this new Phase 3 is $\Delta \varepsilon_{\lg }=-0.16404$ at $\mathrm{T}=313 \mathrm{~K}(\theta=-0.1785)$.

The temperature $\mathrm{T}_{\mathrm{n}+}$ given by (13) is equal to $\mathrm{T}_{\mathrm{n}+}=397.1 \mathrm{~K}\left(124^{\circ} \mathrm{C}\right)$ in perfect agreement with $\mathrm{T}_{\mathrm{w} 2}=124{ }^{\circ} \mathrm{C}$ [12]. There is no effect due to the change of substrate nature in the two referred experiments. The new value of $\mathrm{T}_{\mathrm{w}}$ is due to the glass transition temperature variation.

The thickness of ultrathin crystallized films at $T_{w}$ is $1.5 \mathrm{~nm}$ without grafting and $2.7 \mathrm{~nm}$ with grafting [12]. The initial thicknesses of films are calculated by dividing these thicknesses by the percolation threshold equal to 0.15 and then equal to 10 and $18 \mathrm{~nm}$.

The coherence lengths ratio toward $\mathrm{T}_{3}$ after grafting and before grafting leads to an increase of the prelayer thickness due to the increase of $\mathrm{T}_{\mathrm{g}}$ following (17) [32]:

$\frac{\xi^{\prime}\left(T_{w 2}\right)}{\xi\left(T_{w 1}\right)}=\left(1-\frac{T_{3(2)}}{T_{w 2}}\right)^{-0.88}\left(1-\frac{T_{3(1)}}{T_{w 1}}\right)^{0.88}$,

where $\frac{\xi}{\xi_{0}}=\left(1-\frac{T_{c}}{T_{n+}}\right)^{-0.88}, \mathrm{~T}_{\mathrm{c}}$ being a critical temperature equal to $\mathrm{T}_{3}(1)$ and $\mathrm{T}_{3}(2)$, and $\mathrm{T}_{\mathrm{n}+}=$ $\mathrm{T}_{\mathrm{w} 1}$ or $\mathrm{T}_{\mathrm{w} 2}$ or $\mathrm{T}_{\mathrm{w} 3}$ because the volume fraction of surviving superclusters remains equal to the critical threshold up to $\mathrm{T}_{\mathrm{n}+}$. A coherence length ratio $\xi\left(\mathrm{T}_{\mathrm{w} 2}\right) / \xi\left(\mathrm{T}_{\mathrm{w} 1}\right)=2.46$ is predicted while the experimental value is $2.7 / 1.5=1.8$ [12].

In conclusion, the dewetting temperature $T_{w}$ of prefrozen layers is equal to the temperature $T_{n+}$ of bulk films $\left(h>h_{0}\right)$ where Phase 3 melts. The case of ultrathin films $\left(h<h_{0}\right)$ is discussed in Chapter 4.

\section{3-3 Application to poly ( $\varepsilon$-caprolactone)}

The glass transition temperature of polycaprolactone is $\mathrm{T}_{\mathrm{g} 1}=213 \mathrm{~K}$ [47] and the melting temperature $\mathrm{T}_{\mathrm{m}}=335 \mathrm{~K}[14,19]$. The enthalpy coefficients $\varepsilon_{\mathrm{ls}}$ of Liquid 1 , $\varepsilon_{\mathrm{gs}}$ of Liquid 2, and $\Delta \varepsilon_{\lg }$ of Liquid 3 are determined using (4-9) and given in (18-20):

$$
\begin{aligned}
& \varepsilon_{l s}(\theta)=1.63582\left(1-3.3769 \times \theta^{2}\right), \\
& \epsilon_{g s}(\theta)=1.45373\left(1-2.8333 \times \theta^{2}\right), \\
& \Delta \epsilon_{\lg (\theta)}=0.18209-2.0594 \times \theta^{2} .
\end{aligned}
$$

The enthalpy coefficient $\Delta \varepsilon_{\mathrm{lg}}$ is represented in Figure 2 on Line 1 with $\mathrm{T}_{\mathrm{g} 1}=213 \mathrm{~K}$. Phase 3 is formed at $T_{3}=193.9 \mathrm{~K}$ with an enthalpy coefficient equal to $-\Delta \varepsilon_{\lg 0}=-0.18209$ in (20). This phase survives above $T_{m}$ up to the homogeneous nucleation temperature $T_{n+}=382.3$ $\mathrm{K}\left(111^{\circ} \mathrm{C}\right)$, obeying (13). The dewetting temperature $\mathrm{T}_{\mathrm{w}}$ is expected to occur at $\mathrm{T}_{\mathrm{n}+}$ for a sample which is not grafted.

A thin film of polycaprolactone would be grafted at $\mathrm{T}_{\mathrm{a}}=262.2 \mathrm{~K}$ to obtain $\mathrm{Tw}=353.2$ $\mathrm{K}\left(80.2^{\circ} \mathrm{C}\right)$ as observed by AFM [14]. Its enthalpy coefficient is represented along Line 2 with $\theta_{\mathrm{g} 2}=-0.1403\left(\mathrm{~T}_{\mathrm{g} 2}=288 \mathrm{~K}\right)$. Its value at $\mathrm{T}_{\mathrm{a}}$ is equal to that of initial Phase $3\left(\Delta \varepsilon_{\mathrm{lg}}=-0.18209\right)$. The enthalpy coefficients would be given by (21-23):

$$
\varepsilon_{l s}(\theta)=1.8597\left(1-8.6236 \times \theta^{2}\right) \text {, }
$$


$\epsilon_{g s}(\theta)=1.78955\left(1-5.9744 \times \theta^{2}\right)$,

$\Delta \epsilon_{\lg (\theta)}=0.070149-5.3457 \times \theta^{2}$.

The annealing at $\mathrm{T}_{\mathrm{a}}=262.2 \mathrm{~K}\left(-10.9^{\circ} \mathrm{C}\right)$ increases $\mathrm{T}_{\mathrm{g}}$ up to $\mathrm{T}_{\mathrm{g} 2}=288 \mathrm{~K}$. One more time, $\mathrm{T}_{\mathrm{w}}$ is determined by the glass transition temperature. Here too, the phase transition at $\mathrm{T}_{\mathrm{a}}$ leads to the Phase 3 enthalpy coefficient $-\Delta \varepsilon_{\lg 0}=-0.18209$ in (23). The thickness also increases from $2.36 \mathrm{~nm}$ without grafting to $4.2 \mathrm{~nm}$ with grafting [14]. Equation (17) applied with $\mathrm{T}_{3}(2)=280.7$ $\mathrm{K}, \mathrm{T}_{\mathrm{w} 2}=353.2 \mathrm{~K}, \mathrm{~T}_{3}(1)=193.9 \mathrm{~K}, \mathrm{~T}_{\mathrm{w} 1}=382.3 \mathrm{~K}$ leads to $\xi\left(\mathrm{T}_{\mathrm{w} 2}\right) / \xi\left(\mathrm{T}_{\mathrm{w} 1}\right)=2.17$.

\section{Prefreezing of Poly ( $\varepsilon$-Caprolactone)}

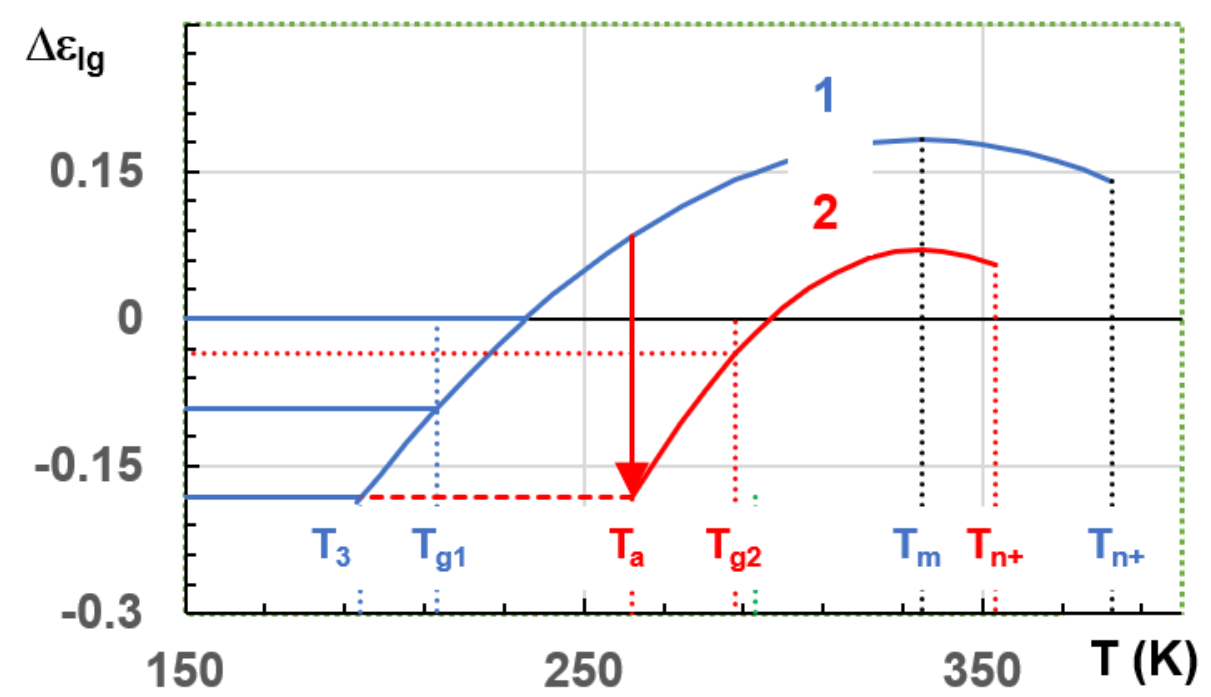

Figure 2: Enthalpy coefficients of bulk poly( $\varepsilon$-caprolactone $)(1)$ and annealed at $T_{a}=262.2 \mathrm{~K}$ (2): $T_{3}=193.9 \mathrm{~K}, T_{g 1}=213 \mathrm{~K}, T_{a}=262.2 \mathrm{~K}\left(-10.9{ }^{\circ} \mathrm{C}\right), T_{g 2}=288 \mathrm{~K}, T_{m}=335 \mathrm{~K}$, and prefreezing temperatures $T_{n+}(2)=353.2 \mathrm{~K}\left(80.1{ }^{\circ} \mathrm{C}\right), T_{n+}(1)=382.3 \mathrm{~K}\left(111^{\circ} \mathrm{C}\right)$. Phase 3 enthalpy coefficient equal to $-\Delta \varepsilon_{l g 0}=-0.18209$ below $T_{a}$.

\section{3-4 Application to polystyrene}

The average glass transition temperature is $373 \mathrm{~K}$, and the specific heat jump $\Delta \mathrm{C}_{\mathrm{p}}$ at $\mathrm{T}_{\mathrm{g}}$ is $30.7 \mathrm{~J} / \mathrm{K} /$ mole [48]. The melting entropy $S_{m}$ per mole is equal to $\Delta C_{p}\left(T_{g}\right) / 1.5=20.47$ $\mathrm{J} / \mathrm{K} / \mathrm{mole}$. This entropy $S_{\mathrm{m}}$ at $\mathrm{T}_{\mathrm{m}}$ is not observed, up to now, in atactic polystyrene, because the annealing time at $\mathrm{T}<\mathrm{T}_{\mathrm{m}}$ is much too long to obtain it. The glass transition temperature of bulk polystyrene is chosen equal to $\mathrm{T}_{\mathrm{g} 1}=379.5 \mathrm{~K}[49,50]$ and the melting temperature $\mathrm{T}_{\mathrm{m}}=548 \mathrm{~K}$ [51]. The melting heat $\mathrm{H}_{\mathrm{m}}$ at $\mathrm{T}_{\mathrm{m}}$ is equal to $20.47 \times 548=11218 \mathrm{~J} / \mathrm{mole} / \mathrm{K}$ instead $20.47 \times 516=$ $10562 \cong 10000 \mathrm{~J} / \mathrm{mole} / \mathrm{K}$ as already proposed [48]. For very thin thickness ( $7 \mathrm{~nm}$ and less) deposited on Pt heater, the overheating peak, resulting from an annealing at $140{ }^{\circ} \mathrm{C}$, is not observed indicating that Phase 3 and configuron phase cannot be formed [52]. The observed glass transition is broadened because broken bonds are formed without attaining their percolation threshold. The thicknesses are too weak. The critical thickness $h_{c}$ of a film authorizing the formation of Phase 3 is obtained dividing the smallest thickness of the adsorbed layer by $\phi=0.15$. For $\mathrm{h}_{\mathrm{c}} \cong 7 \mathrm{~nm}$, the residual thickness would be $7 \times \mathrm{F} \cong 1.05 \mathrm{~nm}$. The thinnest 
thicknesses of the absorbed layer on Si substrate without grafting are 1.3 and $1.5 \mathrm{~nm} \mathrm{[3,} \mathrm{Table}$ 3-1] leading to $\mathrm{h}_{\mathrm{c}} \cong 10 \mathrm{~nm}$.

Two temperatures $\left(150{ }^{\circ} \mathrm{C}\right.$ and $\left.160{ }^{\circ} \mathrm{C}\right)$ of drafting (annealing) are used for films deposited on silicon substrates [ $2,3,11]$. The annealing time is varying from 0.5 to 20 hours. For $\mathrm{T}_{\mathrm{a}}=150{ }^{\circ} \mathrm{C}, 6$ hours are needed to attain the maximum thickness of $5.2 \mathrm{~nm}$ of adsorbed layer [11]. For $\mathrm{T}_{\mathrm{a}}=160{ }^{\circ} \mathrm{C}$, the average value is $4.9 \mathrm{~nm}$ after $24 \mathrm{~h}$ of annealing [3, Table 3-1].

The critical thicknesses $h_{c}$ are equal to $35 \mathrm{~nm}$ for $T_{a}=150{ }^{\circ} \mathrm{C}$ [9] and $33 \mathrm{~nm}$ for $T_{a}=$ $160{ }^{\circ} \mathrm{C}$ [3]. The residual thickness increases from 1-1.5 to 4.9-5.2 $\mathrm{nm}$ with $\mathrm{T}_{\mathrm{a}}$ increasing from 0 to $160{ }^{\circ} \mathrm{C}$ while the critical thickness $h_{c}$ increases from $7-10$ to $36 \mathrm{~nm}$.

\section{Polystyrene (1) and Grafted polystyrene} (2 \& 3) prefreezing

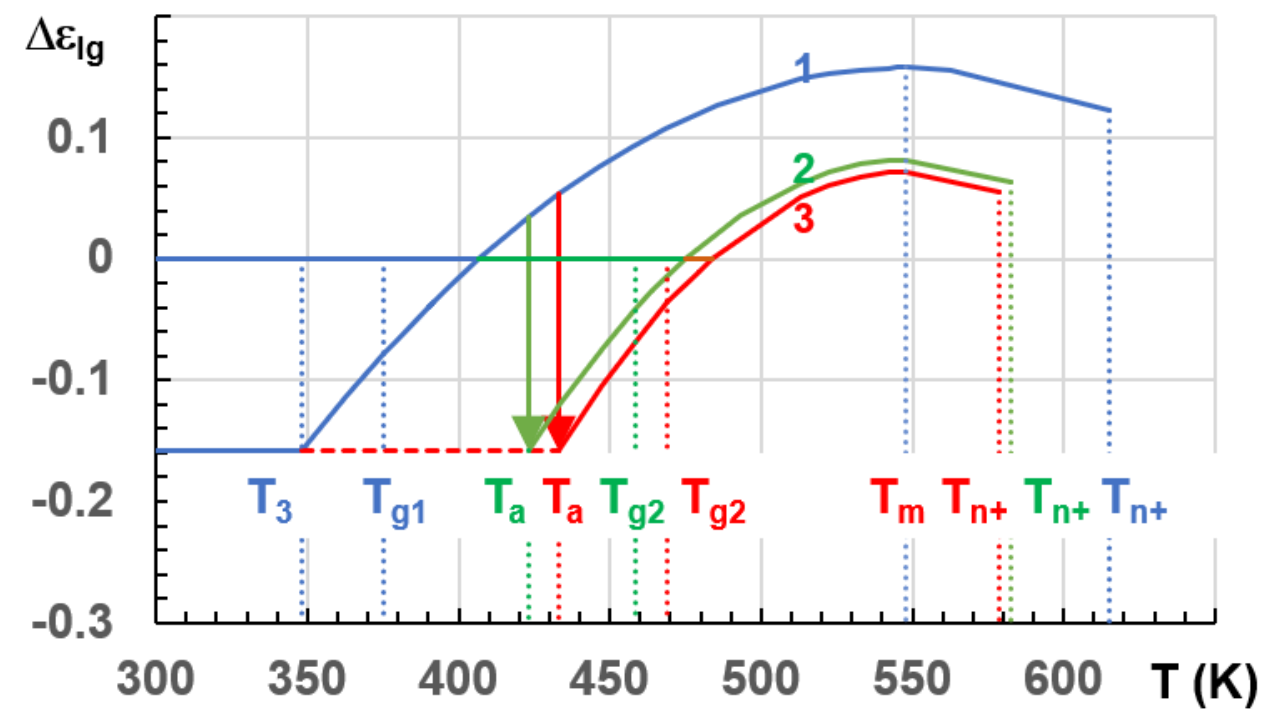

Figure 3: Enthalpy coefficients of bulk polystyrene (1) and annealed at $150{ }^{\circ} \mathrm{C} \mathrm{(2)} \mathrm{and} 160{ }^{\circ} \mathrm{C}$ (3): $T_{3}=353.4 \mathrm{~K}, T_{g 1}=379.5 \mathrm{~K}, T_{a}=423 \mathrm{~K}, T_{a}=433 \mathrm{~K}, T_{g 2}=457.5 \mathrm{~K}, T_{g 3}=468.1 \mathrm{~K}, T_{m}=548 \mathrm{~K}$, and prefreezing temperatures $T_{n+}(3)=578.9 \mathrm{~K}, T_{n^{+}}(2)=583.1 \mathrm{~K}, T_{n^{+}}(1)=613.3 \mathrm{~K}$. Phase 3 enthalpy coefficient equal to $-\Delta \varepsilon_{l g} 0=-0.15374$ below $T_{a}$.

In Figure 3, bulk Phase 3 along line 1 without grafting disappears at $T_{n+}=T_{w 1}=613.3$ $\mathrm{K}$ while along Line 2, it disappears at $\mathrm{T}_{\mathrm{n}+}=\mathrm{T}_{\mathrm{w} 2}=583.1 \mathrm{~K}$ after annealing at $\mathrm{T}_{\mathrm{a}}=423 \mathrm{~K}(150$ $\left.{ }^{\circ} \mathrm{C}\right)$ and along Line 3 at $\mathrm{T}_{\mathrm{n}+}=\mathrm{T}_{\mathrm{w} 3}=578.9 \mathrm{~K}$ after annealing at $\mathrm{T}_{\mathrm{a}}=433 \mathrm{~K}\left(160{ }^{\circ} \mathrm{C}\right)$.

The enthalpy coefficients $\varepsilon_{\mathrm{ls}}$ of Liquid $1, \varepsilon_{\mathrm{gs}}$ of Liquid 2, and $\Delta \varepsilon_{\mathrm{gg}}$ of liquid 3 are determined using (4-9) and given in (24-26):

$$
\begin{aligned}
& \varepsilon_{l s}(\theta)=1.69252\left(1-4.3234 \times \theta^{2}\right), \\
& \epsilon_{g s}(\theta)=1.53877\left(1-3.1703 \times \theta^{2}\right), \\
& \Delta \epsilon_{\lg (\theta)}=0.15374-2.4392 \times \theta^{2} .
\end{aligned}
$$

The enthalpy coefficient $\Delta \varepsilon_{\mathrm{lg}}$ is represented in Figure 3 on Line 1. New Phase 3 is formed at $\mathrm{T}_{3}=353.4 \mathrm{~K}$ with an enthalpy coefficient equal to $-\Delta \varepsilon_{\lg 0}=-0.15374$. This phase survives 
above $\mathrm{T}_{\mathrm{m}}$ up to the homogeneous nucleation temperature $\mathrm{T}_{\mathrm{n}+}=613.3 \mathrm{~K}\left(340.2{ }^{\circ} \mathrm{C}\right)$, obeying (26). The dewetting temperature $T_{w}$ is expected to occur at $T_{n+}$ for a sample which is not grafted.

A thin film of polystyrene is grafted at $\mathrm{T}_{\mathrm{a}}=423 \mathrm{~K}\left(150{ }^{\circ} \mathrm{C}\right)$ leading to $\mathrm{T}_{\mathrm{n}+}=\mathrm{T}_{\mathrm{w}}=583.1$ $\mathrm{K}\left(310{ }^{\circ} \mathrm{C}\right)$. The new enthalpy coefficients are calculated with $\theta_{\mathrm{g} 2}=-0.16513\left(\mathrm{~T}_{\mathrm{g} 2}=457.5 \mathrm{~K}\right)$ using $(4-9,26)$ to obtain the enthalpy coefficient $\Delta \varepsilon_{\lg }=-0.15374$ of initial Phase 3 at $\mathrm{T}_{\mathrm{a}}$. They are given by (27-29):

$$
\begin{aligned}
& \varepsilon_{l s}(\theta)=1.83487\left(1-7.4258 \times \theta^{2}\right), \\
& \epsilon_{g s}(\theta)=1.7523\left(1-5.1838 \times \theta^{2}\right), \\
& \Delta \epsilon_{\lg (\theta)}=0.08257-4.5418 \times \theta^{2} .
\end{aligned}
$$

The enthalpy coefficient $\Delta \varepsilon_{\lg }$ is represented in Figure 3 on Line 2. New Phase 3 is formed at $\mathrm{T}_{\mathrm{a}}=423 \mathrm{~K}$ with an enthalpy coefficient equal to $-\Delta \varepsilon_{\lg 0}=-0.15374$ in (26). This phase survives above $T_{m}$ up to the homogeneous nucleation temperature $T_{n+}=583.1 \mathrm{~K}\left(310^{\circ} \mathrm{C}\right)$, obeying (29). The dewetting temperature $T_{w}$ is expected to occur at $T_{n+}$.

A thin film of polystyrene is grafted at $\mathrm{T}_{\mathrm{a}}=433 \mathrm{~K}\left(160{ }^{\circ} \mathrm{C}\right)$ leading to $\mathrm{T}_{\mathrm{n}+}=\mathrm{T}_{\mathrm{w}}=578.9$ $\mathrm{K}\left(305.8{ }^{\circ} \mathrm{C}\right)$. The enthalpy coefficients are calculated with $\theta_{\mathrm{g} 3}=-0.14573\left(\mathrm{~T}_{\mathrm{g} 3}=468.14 \mathrm{~K}\right)$ using (4-9) to still obtain $\Delta \varepsilon_{\mathrm{lg}}=-0.15374$ at $\mathrm{T}_{\mathrm{a}}$. They are given by (30-32):

$$
\begin{aligned}
& \varepsilon_{l s}(\theta)=1.85427\left(1-8.3265 \times \theta^{2}\right), \\
& \epsilon_{g s}(\theta)=1.78141\left(1-5.778 \times \theta^{2}\right), \\
& \Delta \epsilon_{\lg (\theta)}=0.072865-5.1465 \times \theta^{2} .
\end{aligned}
$$

The enthalpy coefficient $\Delta \varepsilon_{\mathrm{lg}}$ is represented in Figure 3 on Line 3 with $\mathrm{T}_{\mathrm{g} 3}=468.1 \mathrm{~K}$ $\left(195{ }^{\circ} \mathrm{C}\right)$. This phase survives above $\mathrm{T}_{\mathrm{m}}$ up to the homogeneous nucleation temperature $\mathrm{T}_{\mathrm{n}+}=$ $578.9 \mathrm{~K}\left(305.8^{\circ} \mathrm{C}\right)$, obeying (32). The dewetting temperature $\mathrm{T}_{\mathrm{w}}$ of prefrozen layer is expected to occur at $\mathrm{T}_{\mathrm{n}+}$.

A relative increase of $\xi\left(\mathrm{T}_{\mathrm{w} 2}\right) / \xi\left(\mathrm{T}_{\mathrm{w} 1}\right)=1.83$ is predicted applying (17) comparing the increase of coherence lengths when $\mathrm{T}_{\mathrm{w}}$ varies from $613.3 \mathrm{~K}$ to $578.9 \mathrm{~K}$. This value is about the same than that obtained for polyethylene and is much weaker than those obtained after long annealing times of grafting which are equal to about 4 . This thickening could result from the increase of $\xi_{0}$ in (17) and be due to annealing of too-long duration below $\mathrm{T}_{\mathrm{m}}$ which induces more short-range order.

\section{4- Variation $\Delta T_{g} / T_{g}$ proportional to $\left(h_{-} h_{0}\right), \Delta T_{m} / T_{m}$ and $\Delta S_{m} / S_{m}$ for $h<h_{0}$.}

Ultrathin films ( $\left.\mathrm{h}<\mathrm{h}_{0}\right)$ are submitted to a decrease $\Delta \mathrm{T}_{\mathrm{g}}$ of the glass transition temperature depending on $\Delta h=\left(h-h_{0}\right)$. The reduced temperature $\theta_{n+}$ is equal to $\left(-0.38742 \times \theta_{g}\right)$ [29, Equation 28] and $\mathrm{T}_{\mathrm{n}+}$ does not vary with $\Delta \mathrm{h}$ as shown in chapter 3 using the same thermal history. The variation $\Delta \mathrm{T}_{\mathrm{g}}$ is due to change of $\mathrm{T}_{\mathrm{m}}$. Consequently, the relation (33) is obeyed because $\mathrm{T}_{\mathrm{g}}$ and $\mathrm{T}_{\mathrm{m}}$ are bound by linear relation:

$$
\frac{\Delta T_{g}}{T_{g(b u l k)}} \sim \frac{\Delta T_{m}}{T_{m(\text { bulk })}} \sim f(\Delta h / d),
$$

The melting entropy and enthalpy variations depend on $\mathrm{T}_{\mathrm{m}}$ and then (34) is respected: 


$$
\Delta S_{m} / S_{m}=\Delta H_{m} / H_{m}+\Delta T_{m} / T_{m}
$$

The changes $\Delta \mathrm{S}_{\mathrm{m}}$ and $\Delta \mathrm{H}_{\mathrm{m}}$, being proportional to the number of involved atoms and consequently to $\Delta \mathrm{h}$, leads to (35) in agreement with (1) [11]:

$$
\frac{\Delta T_{g}}{T_{g(\text { bulk })}} \sim \frac{\Delta T_{m}}{T_{m(\text { bulk })}} \sim \frac{\Delta S_{m}}{S_{m}} \sim \frac{\Delta h}{d}
$$

The melting temperature $T_{m}$ and melting entropy $S_{m}$ depend on $\Delta h[50,52]$ and respect (35) for $\mathrm{h}<\mathrm{h}_{0}$ because $\Delta \mathrm{T}_{\mathrm{n}+}=0$ whatever $\Delta \mathrm{h}$ may be as shown in Figure 4.

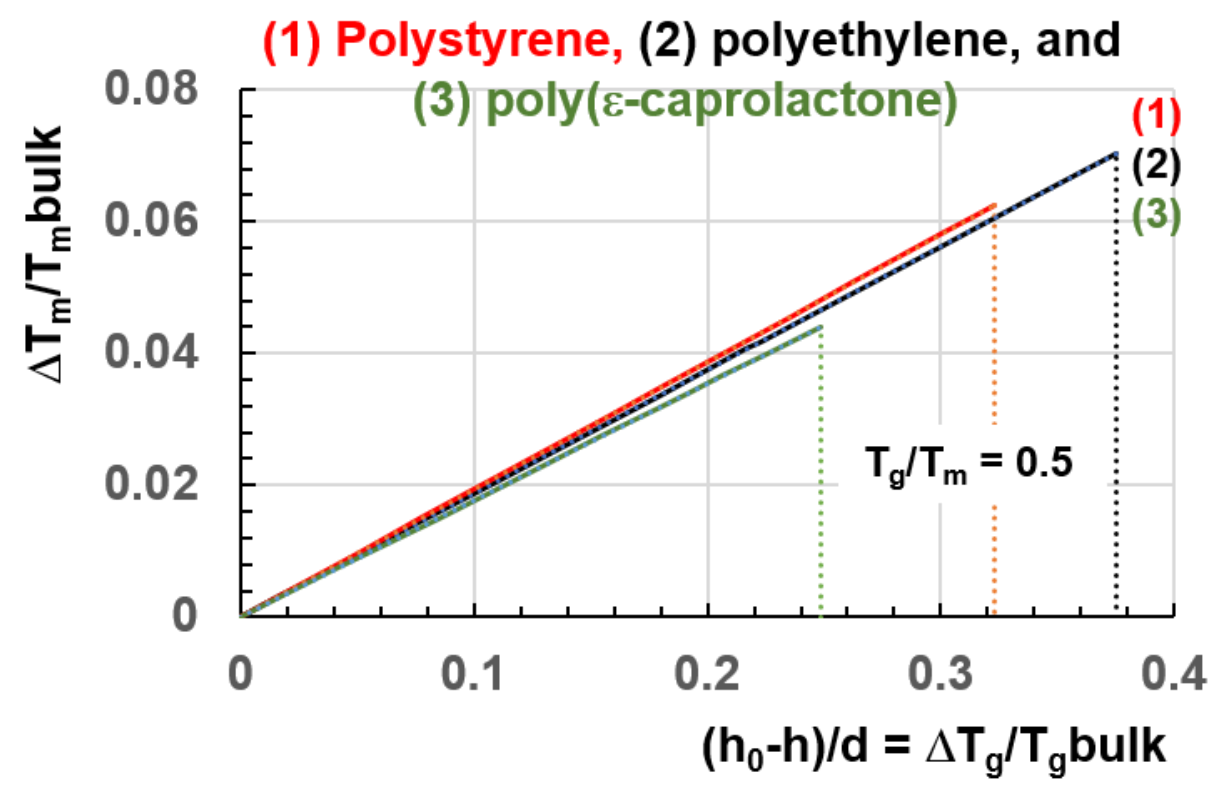

Figure 4: Ratio $-\Delta T_{m} / T_{m}$ bulk plotted versus $\Delta T_{g} / T_{g}$ bulk $=\left(h_{0}-h\right) / h$ for polystyrene $\left(T_{m}\right.$ bulk $=548 \mathrm{~K}, T_{g}$ bulk $\left.=379.5 \mathrm{~K}\right)$, polyethylene $\left(T_{m}\right.$ bulk $=381 \mathrm{~K}, T_{g}($ bulk $\left.)=256 \mathrm{~K}\right)$ and poly $(\varepsilon-$ caprolactone $)\left(T_{m}\right.$ bulk $=335 \mathrm{~K}, T_{g}$ bulk $\left.=213 \mathrm{~K}\right)$. Slope $(1)=0.1934 ;$ slope $(2)=0.1876 ;$ slope (3) $=0.1775$

The slopes $\Delta \mathrm{T}_{\mathrm{m}} / \mathrm{T}_{\mathrm{m}}$ bulk versus $\left(\mathrm{h}_{0}-\mathrm{h}\right) / \mathrm{d}=\Delta \mathrm{T}_{\mathrm{g}} / \mathrm{T}_{\mathrm{g}}$ bulk are weakly varying with the material. The average slope is 0.186 . The temperatures $\mathrm{T}_{\mathrm{g}}$ and $\mathrm{T}_{\mathrm{m}}$ are calculated using $(4,7), \theta_{\mathrm{n}+}=$ $-0.38742 \times \theta_{\mathrm{g}}$ [29] and fixing $\mathrm{T}_{\mathrm{n}+}(1)=613.3, \mathrm{~T}_{\mathrm{n}+}(2)=429.4, \mathrm{~T}_{\mathrm{n}+}(3)=382.3 \mathrm{~K}$. Figure 4 is represented for $\mathrm{T}_{\mathrm{g}} / \mathrm{T}_{\mathrm{m}}>0.5$ because the strong liquid state takes advantage on the fragile one below 0.5 . There is no solution for the homogeneous nucleation temperature of fragile liquid 1 for $\varepsilon_{\mathrm{ls} 0}<1.5$ and (7) cannot be applied [43, equations 24-26].

The ratio $h_{o} / d$ obtained for free surfaces of polystyrene is equal to $69.1 / 213=0.324$ [11] and to the maximum value of $\Delta \mathrm{T}_{\mathrm{g}} / \mathrm{T}_{\mathrm{g}}$ represented in Figure 4. Substrate nature and annealing temperature modify the value of $h_{0} / d$ without changing $T_{n+}$. The prefrozen layer results from a surface energy reduction of tiny crystals surviving at the distance $\mathrm{h}_{0}$, deposited on the substrate, melted at $\mathrm{T}_{\mathrm{n}}$, rebuilt at the same temperature during cooling thanks to a first-order transition [14] and melted at $T_{m}$ giving rise to an adsorbed layer during cooling. Rinsing of films eliminates the weakly bound polymer and reveals the presence of this absorbed polymer phase, tightly bound to the substrate. 
This dense phase, having a thickness depending on the annealing temperature and on the formation time of Phase 3, acts as a second substrate, adding second values of $\mathrm{h}_{0} / \mathrm{d}$ equal to h' $0 /$ d' and of $\mathrm{T}_{\mathrm{g}}$ for $\mathrm{h}<\mathrm{h}^{\prime}{ }_{0}<\mathrm{h}_{0}$ as shown in chapter 6 .

The melting temperature $T_{m}$ and melting entropy $S_{m}$ depend on $\Delta h$ [53-55] and respect (35) for $\mathrm{h}<\mathrm{h}_{0}$ because $\Delta \mathrm{T}_{\mathrm{n}+}=0$ whatever $\Delta \mathrm{h}$ may be.

\section{Film thickness dependence within configuron percolation theory}

Phase transformations are typically described by the concept of symmetry changes e.g. changes of crystalline structures are accompanied by changes of symmetry of atomic distribution in space whereas melting of crystalline solids is accompanied by the reduction of symmetry to a translation invariance of atomic distribution. The glass transition occurs in a nonequilibrium system of atoms disorderly distributed in space and has a dynamic character with the temperature of transformation dependent on cooling rate. Nevertheless, in terms of Ehrenfest classification the glass transition is a typical second-order transformation as it has no latent heat and the first derivative of free energy has no discontinuities whereas the transition is continuous and the second derivative of free energy of system is discontinuous at the glass transition. Indeed, thermal expansion and heat capacity of amorphous materials show a sudden change at the glass transition temperature which enables accurate detection using differential scanning calorimetry measurements. Moreover, namely the discontinuity of second derivative is the basis of standardized test protocols to determine the temperature of glass transition such as the test protocol ASTM D3418 - 15 Standard Test Method for Transition Temperatures and Enthalpies of Fusion and Crystallization of Polymers by Differential Scanning Calorimetry.

Despite of drastic changes of materials properties at the glass transition the structural changes are extremely difficult to reveal directly. This became possible on utilising sophisticated AFM techniques [25], analysis of fifth order susceptibility [56], and analysis of X-ray pair distribution function [35] whereas the theoretical treatment in terms of structural changes are mainly dealt in works that consider association of species i.e. clustering behaviour [26-31]. Structural changes become most evident on analysing the bond system of materials as first proposed by Angel-Rao [33]. We have used the set theory which is a branch of mathematical logic that studies abstract sets as collections of objects. In our case we applied set theory to the set of chemical bonds which can be either intact or broken due to thermal fluctuations. We can focus on just broken bonds termed configurons revealing that at absolute zero $\mathrm{T}=0$ there are no broken bonds at all whereas on increase of temperature more and more broken bonds are formed although up to the glass transition temperature $\mathrm{T}_{\mathrm{g}}$. They are point-like objects and do not form extended associations - clusters. The situation changes drastically when a macroscopic cluster made of broken bonds (configurons) is formed for the first time which penetrates the whole bulk of material. That occurs at the temperature $\mathrm{T}_{\mathrm{g}}$ found from the condition of formation of the percolation cluster made of broken bonds. The configuron percolation theory gives for the glass transition temperature the dependence $T_{g}=H_{d} /\left\{S_{d}+\right.$ $\left.\mathrm{R} \cdot \ln \left[\left(1-\phi_{\mathrm{c}}\right) / \phi_{\mathrm{c}}\right]\right\}$, where $\mathrm{H}_{\mathrm{d}}$ and $\mathrm{S}_{\mathrm{d}}$ are the enthalpy and entropy of the configuron (broken bond) formation, $\phi_{c}$ is the percolation threshold, which determines when the first time a percolation cluster made of broken bonds configurons is formed [26].

The Hausdorff dimension D of the set of chemical bonds at the glass transition changes suddenly as change the material properties. The Hausdorff dimension in our case is equivalent to the simpler Minkowski-Bouligand dimension based on box-counting which is defined as the limit 


$$
D=\lim _{\varepsilon \rightarrow a} \frac{\log N(\varepsilon)}{\log \left(\frac{1}{\varepsilon}\right)}
$$

where $\mathrm{N}(\varepsilon)$ is the number of boxes of side length $\varepsilon$ required to cover the set of bonds. In counting procedure, we start with macroscopic large lengths diminishing them step by step to microscopic scales. In mathematics the limit is formally drawn to zero whereas we accounted that the minimal length is equal to the bond size $a=1 / 2$ i.e. half of interatomic distance 1 . The set of broken bonds thus has $\mathrm{D}=0$ below the $\mathrm{T}_{\mathrm{g}}$, and $\mathrm{D}=2.55 \pm 0.05$ above [26].

The configuron percolation theory envisages the size dependence of glass transition temperature as follows [57]:

$T_{g}(h)=T_{g}(b u l k)\left[1-\left(\frac{\alpha_{c p t}}{h}\right)^{\delta}\right]$

where $\alpha_{c p t}=\xi_{0}\left[7.843 \mathrm{RT}_{\mathrm{g}}(\text { bulk }) / \mathrm{H}_{\mathrm{d}}\right]^{v}, \xi_{0}$ is a certain elementary length of the order of the bond length, $\delta=1 / v$, and $v=0.88$ is the critical exponent. As emphasized above (see i.e. equation (1)), the glass transition temperature of solid ultrathin films $\mathrm{T}_{\mathrm{g}}(\mathrm{h})$ reduces from its value in bulk materials $\mathrm{T}_{\mathrm{g}}$ (bulk) with the reduction of film thickness $h$. Reference [11] gives the linear dependence given by equation (1) while earlier [58], it was suggested the non-linear relationship (37) of measured glass transition temperature $T_{g}(h)$ for a polystyrene film of thickness $h$ by equation :

$T_{g}(h)=T_{g}(b u l k)\left[1-\left(\frac{\alpha}{h}\right)^{\delta}\right]$

with best fit parameters describing the data $\alpha=320 \mathrm{~nm}$, and $\delta=1.8$. The configuron percolation theory of glass transition gives as we see a smaller $\delta=1.136$ close to experiment size dependence of glass transition temperature for $\mathrm{h}>15 \mathrm{~nm}$ with $\mathrm{h}_{0} \cong 50 \mathrm{~nm}$. Equation (37) can be linearised for thicknesses $\mathrm{h}<<\mathrm{h}_{0}$ as follows:

$T_{g}(h)=T_{g}($ bulk $)\left\{\left[1-\left(\frac{\alpha_{c p t}}{h_{0}}\right)^{\delta}\right]-\delta\left(\frac{\alpha_{c p t}}{h_{0}}\right)^{\delta} \frac{h_{0}-h}{h_{0}}\right\}$

The linear law below $\mathrm{h}_{0}$ is needed to explain that the melting temperature $\mathrm{T}_{\mathrm{n}+}$ of bulk materials does not vary for thickness as thin as $6 \mathrm{~nm}$ [12].

\section{6- The double glass transition of ultrathin films of polystyrene}

Double glass transition temperatures are observed in four ultrathin films deposited on silicon with thicknesses between 7.9 and $11.85 \mathrm{~nm}$ after rinsing with various solvents and 24 hours of post-annealing at $120^{\circ} \mathrm{C}$ [3, Tables 5-2 and 5-7]. The two glass transition temperatures are 85.1 and $127.2^{\circ} \mathrm{C}$ for a thickness $\mathrm{h}$ of $7.9 \mathrm{~nm}, 89$ and $132.7^{\circ} \mathrm{C}$ for $\mathrm{h}=7.97 \mathrm{~nm}, 93.7$ and $133.5{ }^{\circ} \mathrm{C}$ for $\mathrm{h}=8.66 \mathrm{~nm}$ and 97.6 and $138.9{ }^{\circ} \mathrm{C}$ for $\mathrm{h}=11.85 \mathrm{~nm}$. The thickness of residual layer $h_{r}$ equal to $F h \cong 0.15 h$ is plotted versus the lowest value of $T_{g}$ in Figure 5 . The residual thickness cannot be lower than $1.2 \mathrm{~nm}$ and then $\mathrm{h}_{\mathrm{c}} \cong 8 \mathrm{~nm}$.

These films, annealed 24 hours at $120^{\circ} \mathrm{C}$, have a calculated glass transition temperature $\mathrm{T}_{\mathrm{g}}$ (bulk) $=424.6 \mathrm{~K}$, lowest limits for $\mathrm{T}_{\mathrm{g}}$ equal to $356 \mathrm{~K}$ as shown in Figure $5,395 \mathrm{~K}$ as shown in Figure $6, \Delta \mathrm{T}_{\mathrm{g}} / \mathrm{h}_{\mathrm{r}} \cong 8.15$ and $\Delta \mathrm{T}_{\mathrm{g}} /(\mathrm{h}-1.2)=1.598$. The two thicknesses defining the effective interaction ranges are $\mathrm{h}^{\prime}{ }_{0}=\mathrm{h}_{\mathrm{r}}=\Delta \mathrm{T}_{\mathrm{g}} / 8.15=68.4 / 8.15=8.39 \mathrm{~nm}$ with d' $=\mathrm{h}^{\prime}{ }_{0} \times \mathrm{T}_{\mathrm{g}} / \Delta \mathrm{T}_{\mathrm{g}}=$ $8.39 \times 424.6 / 68.4=52 \mathrm{~nm}$ and $\left(\mathrm{h}_{0}-1.2\right)=\Delta \mathrm{T}_{\mathrm{g}} / 1.598=29.6 / 1.598=18.5 \mathrm{~nm}$ with $\mathrm{d}=$ 
$18.5 \times 424.6 / 29.6=265 \mathrm{~nm}$ using the two values of $\mathrm{T}_{\mathrm{g}}$ for each film deposited on the silicon substrate and on the adsorbed layer (inside the uncertainty on $h$ and $T_{g}$ ). Other values of $T_{g}(h)$ confirm an increase of $\Delta \mathrm{T}_{\mathrm{g}} / \Delta \mathrm{h}$ for $\mathrm{h}<10 \mathrm{~nm}$ [59] in agreement with a change of $\mathrm{h}_{0} / \mathrm{d}$. The same phenomenon of two glass transition temperatures has been attributed to a layer tightly bound to the substrate and to a weakly bound film [60]. The adsorbed layer acts as a true phase having an interface energy which is distinct from the bulk amorphous phase and is the melted prefrozen layer below $T_{m}$ [14]. The prefrozen layer could remain a dense liquid phase 3 above $T_{m}$ without being crystallized in atactic polystyrene, a $2 \mathrm{D}$ nanoconfinement being responsible of its formation.

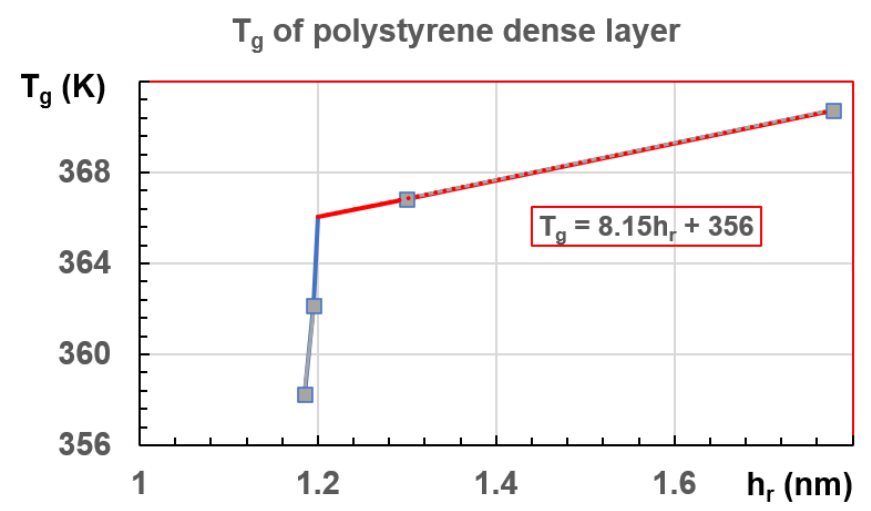

Figure 5: Lowest glass transition temperatures of residual polystyrene layer deposited on silicon substrates [3] versus its thickness $h_{r}$ obtained applying $h_{r}(\mathrm{~nm})=F . h \cong 0.15 \mathrm{~h}, \mathrm{~h}$ being the film thickness. $T_{g}=\left[8.15 h_{r}+83.1\right]$ above $T_{g}=93.7^{\circ} \mathrm{C}$.

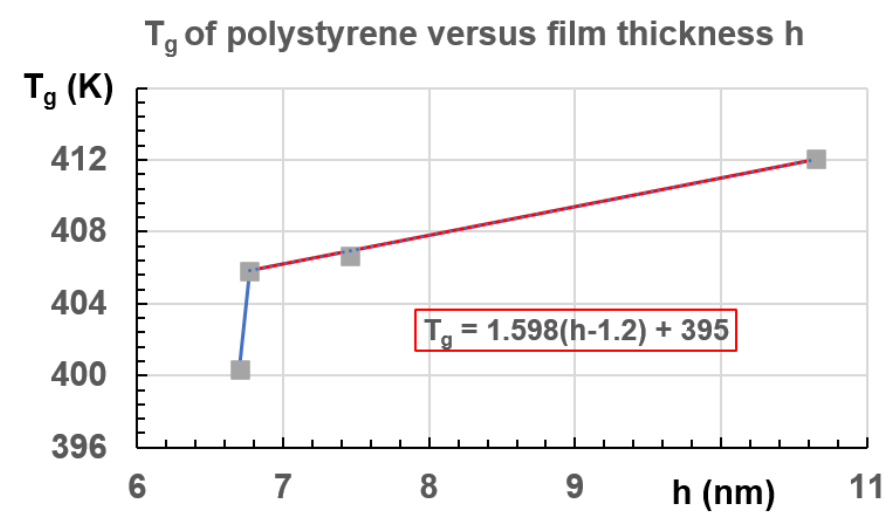

Figure 6: Highest glass transition temperatures of ultrathin films with a thickness equal to ( $h$ 1.2) $\mathrm{nm}$ beyond the residual layer thickness $h_{r}=1.2 \mathrm{~nm}$ for $h<12 \mathrm{~nm} . T_{g}\left({ }^{\circ} \mathrm{C}\right)=[1.627(\mathrm{~h}-1.2)$ $+121.5]$ above $T_{g}=132.7^{\circ} \mathrm{C}$.

\section{7- Melting of grafted layers at $T_{g}(h<8 ~ n m)$}

Uniform ultrathin layers are rinsed at room temperature to obtain grafted layers after elimination of the weakly bound polymer covering them. They are prepared below $\mathrm{T}_{\mathrm{g}}$ with thicknesses smaller than the critical one $h_{c} \cong 8 \mathrm{~nm}$. These glassy grafted layers melt at $T=T_{g}$ and form a liquid phase without Phase 3 because this configuron phase is formed above $T_{g}$ in these polymers. The specific heat jump is broadened because the critical phenomenon 
associated with the formation of configuron thermodynamic phase at $T_{g}$ has disappeared. The melting of grafted layers is accompanied by dewetting as observed at $\mathrm{T}_{\mathrm{n}+}$ because the liquid films are unstable. Table 3-1 in [3] lists wetting and dewetting after post-annealing at $120{ }^{\circ} \mathrm{C}$ of polystyrene films with $\mathrm{h}=7 \mathrm{~nm}$. All films having $\mathrm{T}_{\mathrm{g}}>120^{\circ} \mathrm{C}$ are not dewetted because they contain Phase 3 while those with $\mathrm{T}_{\mathrm{g}}<120^{\circ} \mathrm{C}$, are dewetted.

\section{8- Melting of ordered ice in nanotubes}

Equation (13) predicts the melting temperature $T_{n+}$ of surviving crystals above $T_{m}$ in all overheated liquids including ice when Phase 3 is first formed at lower temperatures [31]. These entities represent about $15 \%$ of the liquid volume after supercooling below $\mathrm{T}_{\mathrm{g}}$ and reheating above $\mathrm{T}_{\mathrm{m}}$. The formation of prefrozen layers on various substrates through first-order transitions above $T_{m}$ results from nanoconfinement occurring in bulk liquid at interface proximity [12-14]. Ice in bulk water has a temperature $\mathrm{T}_{\mathrm{n}+}$ equal to room temperature $295 \mathrm{~K}$. Ice prefrozen layers are expected to be formed below $\mathrm{T}_{\mathrm{n}+}$ and melted above. There are several observations and simulations of "ordered water monolayer that does not completely wet water" showing that water droplets cover the ordered monolayer [61]. A phase diagram of ice in single-walled carbon nanotubes at atmospheric pressure summarizes melting points as a function of diameter up to $1.7 \mathrm{~nm}$. The highest melting point $290 \mathrm{~K}$ for a diameter of $1.08 \mathrm{~nm}$ is nearly equal to $T_{n+}$. The predicted melting points are represented for several diameters in Figure 7 [62]. Phase transitions in ordered hexagonal ice structure which is considered as representative of confined 2D water at low density is still investigated by molecular-dynamics simulations. For bilayer hexagonal ice, a first-order transition is predicted in the temperature range between $290 \mathrm{~K}$ and $300 \mathrm{~K}$ in agreement with $\mathrm{T}_{\mathrm{n}+}=295 \mathrm{~K}$ [63]. The temperature $\mathrm{T}_{\mathrm{n}+}$ is evaluated for various diameters of nanotubes and compared with simulation results of [64] in Figure 7.

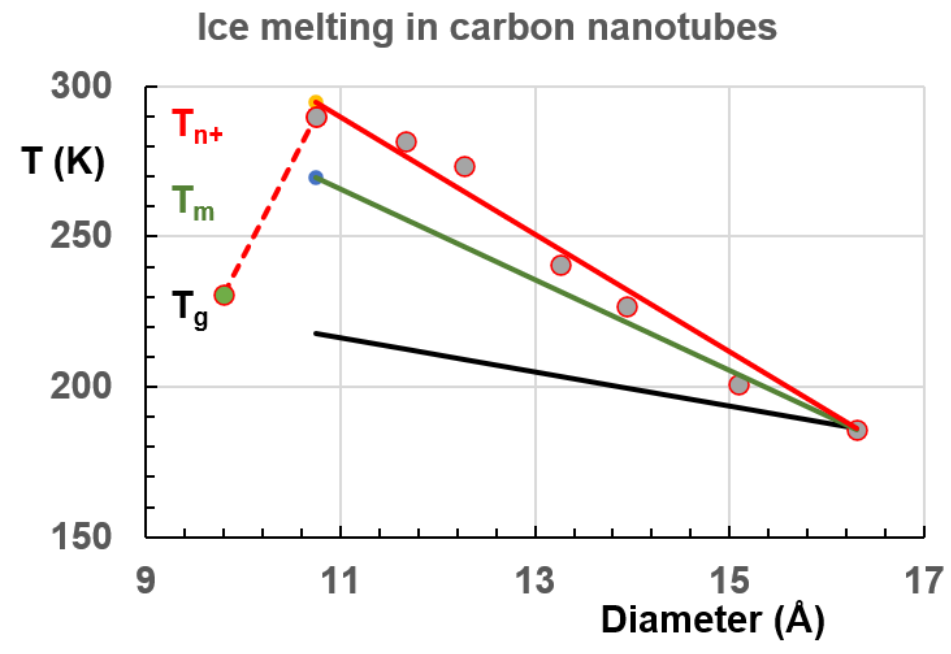

Figure 7: Ice melting in nanotubes. Melting and glass transition temperatures versus nanotube diameters in Angströms. The maximum values at $295 \mathrm{~K}$ characterize the prefrozen layer while minimum values are obtained for $T_{n+}=T_{m}=T_{g} \cong 186 \mathrm{~K}$. Circles representing molecular dynamics simulations from [62]. Model predictions of $T_{n+}, T_{m}$, and $T_{g}$ are represented by continuous straight lines.

The glass transition temperature $\mathrm{T}_{\mathrm{g}}$ is a linear function of $\mathrm{T}_{\mathrm{m}}$ as shown in (4). It is also true for $T_{n+}$ which is a linear function of $T_{g}$ as shown in (40) [29, equation 18]: 
$\theta_{n+}=-0.38742 \times \theta_{g}$

The maximum temperatures $\mathrm{T}_{\mathrm{n}+}, \mathrm{T}_{\mathrm{m}}$ and $\mathrm{T}_{\mathrm{g}}$ are equal to $295,273.1$, and $217.7 \mathrm{~K}$, characterizing bulk water and $\mathrm{T}_{\mathrm{n}+}$ is the maximum melting temperature of prefrozen layer. This melting temperature $\mathrm{T}_{\mathrm{n}+}$ is the same in a nanotube of $1.08 \mathrm{~nm}$ and is strongly reduced to $186 \mathrm{~K}$ for 1.68 $\mathrm{nm}$. The temperatures $\mathrm{T}_{\mathrm{n}+}, \mathrm{T}_{\mathrm{g}}$, and $\mathrm{T}_{\mathrm{m}}$ are minimum and altogether equal to $\cong 186 \mathrm{~K}$ as shown in Figure 7 by the fall of the melting temperature $\mathrm{T}_{\mathrm{n}+}$ below $1.08 \mathrm{~nm}$. In this situation, the enthalpy coefficients are $\varepsilon_{\mathrm{ls} 0}=\varepsilon_{\mathrm{gs} 0}=2$ and $\mathrm{T}_{\mathrm{n}+}$ obeys a linear law between $295 \mathrm{~K}$ and $186 \mathrm{~K}$.

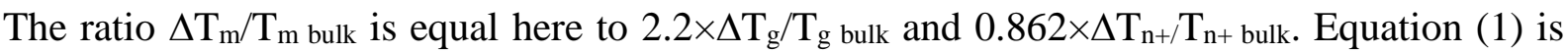
respected with $\mathrm{h}_{0}=1.08 \mathrm{~nm}$ and $\mathrm{d}=3.78 \mathrm{~nm}$. Another melting-freezing transition of water monolayer confined between two non-flat phosphorene plates is expected at $230 \mathrm{~K}$ as the relative position of the two plates changes from 0.1 to $0.44 \mathrm{~nm}$. In this case, the influence of these two plates is still stronger [64].

Our model is based on the formation at $\mathrm{T}_{\mathrm{n}+}$, in a bulk liquid, of confined prefrozen layer without consideration of the solid layer structure and the nature of the substrate. Values of $T_{g}, T_{m}$ and $\mathrm{T}_{\mathrm{n}+}$ compared with those of bulk materials depend on interface nature and thermal history. The crystallized layer, which is formed by heating the supercooled liquid, can stay crystallized down to the lowest temperatures after new cooling. A second heating melts it at the same temperature $\mathrm{T}_{\mathrm{n}+}$.

\section{9- Rejuvenation of crystallization scenario of plastic crystals in $\mathrm{CCl}_{4}$ and ethanol}

Plastic crystals are formed at a temperature T' ${ }_{\mathrm{m}}$ weaker or higher than the melting temperature $\mathrm{T}_{\mathrm{m}}$. Two examples are presented.

\section{9-1 Formation of plastic crystals above $T_{m}$ in tetrachloromethane}

Crystalline tetrachloromethane $\mathrm{CCl}_{4}$ is viewed as plastic crystal because it undergoes two main transitions from solid-to-solid with high entropy and solid-to-liquid with low entropy [65]. The glass transition of samples rapidly cooled from the liquid state, starts at $78 \mathrm{~K}$ characterized by a specific heat jump [66]. This material has two melting temperatures $\mathrm{T}_{\mathrm{m}}=225.3 \mathrm{~K}$ and $\mathrm{T}^{\prime}{ }_{\mathrm{m}}=$ $250.3 \mathrm{~K}$ [65] after slow cooling down to $17 \mathrm{~K}$ followed by slow heating. The glass transition temperature is fixed at $\mathrm{T}_{\mathrm{g}}=80 \mathrm{~K}$ as shown in Figure 8 to determine the enthalpy coefficients $\varepsilon_{\mathrm{ls} 0}, \varepsilon_{\mathrm{gs} 0}$ and $\Delta \varepsilon_{\mathrm{lg} 0}$ of liquids 1,2 and 3 respectively. The experimental points of heat capacity of Hicks et al are plotted in Figure 8 on Lines 3, 2 and 1. Line 1 is prolonged using (41) which leads to $\mathrm{C}_{\mathrm{pl}}=122.53 \mathrm{~J} / \mathrm{K} / \mathrm{mole}$ at $\mathrm{T}_{\mathrm{g}}=80 \mathrm{~K}$ :

$C_{p l}(J / K$. mole $)=0.04283 \times T(K)+119.12$

The jump $\Delta \mathrm{C}_{\mathrm{p}}\left(\mathrm{T}_{\mathrm{g}}\right)$ is equal to $(122.53-58.63)=63.9 \mathrm{~J} / \mathrm{K} / \mathrm{mole}$ with a heat capacity of crystals $\mathrm{C}_{\mathrm{pc}}$ equal to $58.63 \mathrm{~J} / \mathrm{K} / \mathrm{mole}$. The heat capacity excess $\Delta \mathrm{C}_{\mathrm{p}}$ of Phase 3 is given by (42) and determines the melting entropy $\mathrm{S}_{\mathrm{m}}$ from the knowledge of $\Delta \mathrm{C}_{\mathrm{p}}$ at $\mathrm{T}_{\mathrm{g}}$ which is equal to 63.9 $\mathrm{J} / \mathrm{K} / \mathrm{mole}$ :

$\Delta C_{p}=2 \theta S_{m}\left(\varepsilon_{l s 0} / \theta_{0 m}^{2}-\varepsilon_{g s 0} / \theta_{0 g}^{2}\right)$ 
The contribution of Phase 3 being proportional to $\theta=\left(T-T_{m}\right) / T_{m}$ and equal to zero at $T_{m}=$ $225.3 \mathrm{~K}$ is described by the difference between lines 1 and 2 . The straight line 2 extends from $\mathrm{C}_{\mathrm{pc}}=58.3$ at $\mathrm{T}_{\mathrm{g}}=80 \mathrm{~K}$ to $\mathrm{C}_{\mathrm{pl}}=128.77$ at $\mathrm{T}_{\mathrm{m}}=225.3 \mathrm{~K}$. The lowest value of first-order transition temperatures is chosen for $T_{m}$ because it is not possible to predict a value of $T_{g}$ with that of $T^{\prime}{ }_{m}$ using our model and the entropy variation is much higher and involves more atoms.

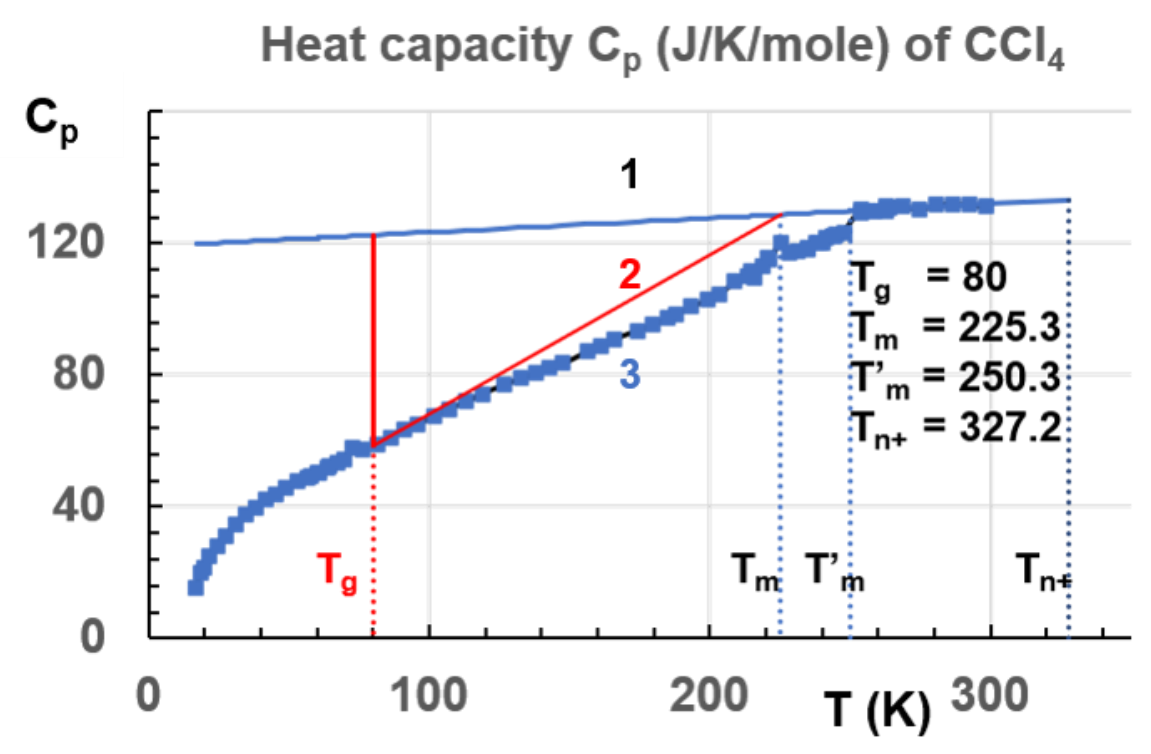

Figure 8: Heat capacity of $\mathrm{CCl}_{4}$ : 1- liquid heat capacity; 2- The Phase 3 heat capacity contribution is defined at each temperature by the difference between Line 1 and Line 2; 3Heat capacity of crystallized phase [65]. Recovered enthalpy $\delta H: \delta H=O$ at $T_{g}=80, \delta H=4573$ at $T_{m}=225.3, \delta H=2513$ at $T^{\prime}{ }_{m}=250.3, \delta H=375 ? \mathrm{~J} / \mathrm{K} / \mathrm{mole}$ at $T_{n+}=327.2 \mathrm{~K}$.

Liquids 1,2 and 3 are strong because $\theta_{\mathrm{g}}=\left(\mathrm{T}_{\mathrm{g}}-\mathrm{T}_{\mathrm{m}}\right) / \mathrm{T}_{\mathrm{m}}=-0.64523$ is smaller than -0.5 . The parameters $\varepsilon_{\mathrm{ls} 0}$ and $\varepsilon_{\mathrm{gs} 0}$ at $\theta=0$ are determined with (2) for $\Delta \varepsilon=0$ or with (43) and (44):

$$
\begin{aligned}
& \varepsilon_{l s 0}=\left(3 \theta_{g}+2\right) /\left(1-\theta_{g}^{2} / \theta_{0 m}^{2}\right), \\
& \varepsilon_{g s 0}=\left(3 \theta_{g}+2\right) /\left(1-\theta_{g}^{2} / \theta_{0 g}^{2}\right),
\end{aligned}
$$

where the VFT temperatures $\mathrm{T}_{0 \mathrm{~m}}$ and $\mathrm{T}_{0 \mathrm{~g}}$ of strong liquids 1 and 2 are chosen equal to $\mathrm{T}_{\mathrm{m}} / 3=$ $75.1 \mathrm{~K}$ and $\mathrm{T}_{0 \mathrm{~g}}=0 \mathrm{~K}\left(\theta_{\mathrm{g}}=-0.64523, \theta^{-2} 0 \mathrm{~m}=2.25, \theta^{-2} 0 \mathrm{~g}=1\right)$.

The thermal variations of enthalpy coefficients are given in (45-47):

$$
\begin{aligned}
& \varepsilon_{l s}=1.01634\left(1-2.25 \times \theta^{2}\right), \\
& \varepsilon_{g s}=0.11018\left(1-\theta^{2}\right), \\
& \Delta \varepsilon_{l s}=0.90616-2.1766 \times \theta^{2},
\end{aligned}
$$

The experimental melting enthalpies at $T_{m}$ and $T^{\prime}{ }_{m}$ are 4573 and $2513 \mathrm{~J} / \mathrm{K} / \mathrm{mole}$. These two values are an average of measurements assembled by [65]. The theoretical melting entropy $\mathrm{S}_{\mathrm{m}}$ $=22.75 \mathrm{~J} / \mathrm{K} / \mathrm{mole}$ and enthalpy $\mathrm{H}_{\mathrm{m}}=5127 \mathrm{~J} /$ mole deduced from (42) are comparable to the 
experimental values. The enthalpy recovery at $\theta_{\mathrm{n}+}=\Delta \varepsilon_{\mathrm{lg}}=0.4552$, calculated with (47) in the absence of phase transition at $\mathrm{T}^{\prime}{ }_{\mathrm{m}}$, is $0.4552 \times \mathrm{S}_{\mathrm{m}} \times \mathrm{T}_{\mathrm{m}}=2334 \mathrm{~J} / \mathrm{mole}\left(\mathrm{T}_{\mathrm{n}+}=327.2 \mathrm{~K}\right)$. The total enthalpy recovery is predicted equal to $5127+2334=7461 \mathrm{~J} / \mathrm{mole}$ while the measured values are $4573+2513=7086 \mathrm{~J} / \mathrm{mole}$. An enthalpy of $375 \mathrm{~J} / \mathrm{mole}$ is missing and could correspond to $15 \%$ of the melting enthalpy at $T^{\prime}{ }_{m}$. This quantity would be recovered by heating up to $T_{n+}$ which is smaller than the vaporization temperature at $348.5 \mathrm{~K}$. Crystals surviving between $\mathrm{T}^{\prime} \mathrm{m}$ and $\mathrm{T}_{\mathrm{n}+}$ melts at $\mathrm{T}_{\mathrm{n}+}$. By cooling from $\mathrm{T}<\mathrm{T}_{\mathrm{n}+}$, these crystals would grow and percolate at $\mathrm{T}^{\prime}{ }_{\mathrm{m}}$ inducing crystallization. There are other crystalline phases between $T_{m}$ and $T_{m}{ }_{m}$ depending on other thermal history [67].

\section{9-2 Formation of plastic crystals below $T_{m}$ in ethanol}

Ethanol melting occurs at $T_{m}=152 \mathrm{~K}$ and extends up to $174 \mathrm{~K}$. Heat capacities $C_{p}$ are represented in Figure 9 along Line 1 for crystals, Line 3 for undercooled liquid and Line 2 for plastic phase using measurements of $\mathrm{O}$. Haida et al [68]. The heat capacity is weaker along Line 2 than along Line 3. The undercooled liquid and plastic crystal have the same glass transition temperature at $\mathrm{T}_{\mathrm{g} 1}=97 \mathrm{~K}$. The heat capacity jumps are equal to the differences between Line 1 and Line 3 along $\mathrm{AB}=44 \mathrm{~J} / \mathrm{K} / \mathrm{mole}$, and Line 1 and Line 2 along $\mathrm{CB}=33.8 \mathrm{~J} / \mathrm{K} / \mathrm{mole}$. Plastic crystals undergo a second glass transition temperature at $\mathrm{T}_{\mathrm{g} 2}=\mathrm{T}_{\mathrm{m}}{ }_{\mathrm{m}}=126 \mathrm{~K}$.

Latent heats of transformation at $\mathrm{T}_{\mathrm{m}}=152 \mathrm{~K}$ and $\mathrm{T}_{\mathrm{m}}=126 \mathrm{~K}$ are equal to 4458 along $\mathrm{GH}$ after correction (the measured value $4931 \mathrm{~J} / \mathrm{K} / \mathrm{mole}$ is overestimated because it includes enthalpy recovered at $\mathrm{T}_{\mathrm{n}+}$ ) and $663 \mathrm{~J} / \mathrm{K} /$ mole along EF. The total latent heat is exothermic at $\mathrm{T}$ ' $\mathrm{m}$ combining endothermic plastic crystal melting along FD and exothermic crystal formation along EF. This last crystal is fully melted along $\mathrm{GH}$ at $\mathrm{T}_{\mathrm{m}}=152 \mathrm{~K}$.

\section{$\mathrm{C}_{\mathrm{p}}(\mathrm{T})(\mathrm{J} / \mathrm{K} / \mathrm{mole})$ of ethanol}

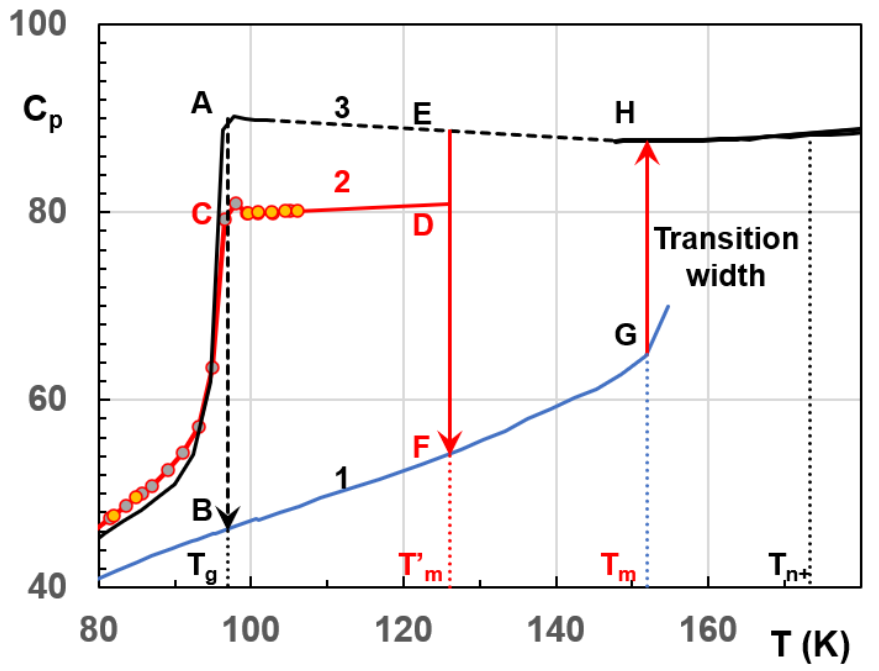

Figure 9: Heat capacity of ethanol reproducing measurements of [68]. 1- crystal, 2- plastic crystal, 3- undercooled liquid; $\mathrm{T}_{\mathrm{g}}=97 \mathrm{~K}, \mathrm{~T}^{\prime}{ }_{\mathrm{m}}=126 \mathrm{~K}, \mathrm{~T}_{\mathrm{m}}=152 \mathrm{~K}, \mathrm{Tn}_{+}=173.3 \mathrm{~K}$. Transition width of melting between $\mathrm{T}_{\mathrm{m}}=152 \mathrm{~K}$ and $\mathrm{T}_{\mathrm{n}+}=173.3 \mathrm{~K}$.

The heat capacity jump at $\mathrm{T}_{\mathrm{g}}$ is equal to $1.5 \mathrm{~S}_{\mathrm{m}}$. The experimental amplitude of the jump at $\mathrm{T}_{\mathrm{g} 1}$ $=97 \mathrm{~K}$ is $\mathrm{AB}=44 \mathrm{~J} / \mathrm{K} /$ mole leading to $S_{\mathrm{m}}=4458 / 152=29.33 \mathrm{~J} / \mathrm{K} / \mathrm{mole}$. The transition of glass phase at $\mathrm{T}_{\mathrm{g} 2}=126 \mathrm{~K}$ toward the liquid phase induces an experimental jump $\Delta \mathrm{C}_{\mathrm{p}}=\mathrm{DE} \cong 7.7$ 
$\mathrm{J} / \mathrm{K} / \mathrm{mole}$ and a melting enthalpy of this intermediate glass phase equal to $7.7 / 1.5 \times 126 \cong 647$ $\mathrm{J} / \mathrm{K} / \mathrm{mole}$ comparable to $663 \mathrm{~J} / \mathrm{mole}$. The heat capacity of two glassy phases along AE and CD are not separated by a constant value because a fraction $\mathrm{f}$ of plastic phase is crystallized and equal to $\mathrm{ED} / \mathrm{EF}=7.7 / 34.6=0.22$. This fraction $f$ increases the value of $\mathrm{C}_{\mathrm{p}}$ at the point $\mathrm{D}$ and reduces ED.

The configuron model predicts percolation at $\mathrm{T}_{\mathrm{g}}$ of about $15 \%$ of sample volume occupied by superclusters. Here, these entities are crystallized in glass phase below $126 \mathrm{~K}$ and crystallized up to $\mathrm{T}_{\mathrm{n}+}=173.3 \mathrm{~K}$ for $\theta_{\mathrm{n}+}=\Delta \varepsilon_{\mathrm{lg}}=0.1402$ using (39) [29]. This enthalpy coefficient is nearly equal to the ratio of latent heats $663 / 4428=0.1487$. Haida et al also observe that melting of crystals extends from 152 to $174 \mathrm{~K}$ and consequently up to $\mathrm{T}_{\mathrm{n}+}=173.3 \mathrm{~K}$ [68].

In conclusion of this chapter, this ethanol study shows, for the first time, that these crystallized entities induce, by heating, the full crystallization at the percolation threshold and build the glassy skeleton of the plastic phase below $\mathrm{T}_{\mathrm{g} 2}=126 \mathrm{~K}$ down to $\mathrm{T}_{\mathrm{g} 1}=97 \mathrm{~K}$ and $0 \mathrm{~K}$. Any molecular compound seems to have a liquidus temperature equal to $\mathrm{T}_{\mathrm{n}+}$. The enthalpy recovery at $\mathrm{T}_{\mathrm{n}}$ does not seem to be associated with a first-order transition because the enthalpy increases with temperature up to $T_{n+}$ without changing the entropy of fusion except for the first-order transition associated with the formation and melting of the prefrozen layer.

\section{Conclusions}

A new description of melt-memories is proposed using converging concepts of 1broken bond percolation at $\mathrm{T}_{\mathrm{g}}$ by heating amorphous phase through $\mathrm{T}_{\mathrm{g}}$ and 2-presence of two liquids 1 and 2, describing formation of new thermodynamic phase called Phase 3 at $T_{3}<T_{g}$. These two thermodynamic phases (Phase 3 and configuron phase) are the same and give rise to an ordered liquid 3 from $\mathrm{T}_{\mathrm{g}}$ to $\mathrm{T}_{\mathrm{n}+}>\mathrm{T}_{\mathrm{m}}$ involving a maximum volume fraction equal to the percolation threshold $\mathrm{F}=0.15 \pm 0.01$.

A prefrozen crystallized layer is formed, melted at the temperature $T_{n+}$, depending on the annealing temperature $T_{a}$ used to graft a dense layer on the substrate below $T_{m}$. After formation of Phase 3 by annealing at $T_{a}$ and crystallization, tiny crystals, surviving above $T_{m}$ between the substrate and a maximum thickness $h_{0}$ above $T_{m}$ are assembled in prefrozen layers of minimum thickness $h_{r}$ reducing their surface energy. This formation on various substrates through first-order transitions above $\mathrm{T}_{\mathrm{m}}$ results from nanoconfinement occurring in bulk liquid at interface proximity for $\mathrm{h}<\mathrm{h}_{0}$. The glass transition temperatures of ultrathin films of thickness $\mathrm{h}<\mathrm{h}_{0}$ are linear functions of $\Delta \mathrm{h}=\left(\mathrm{h}-\mathrm{h}_{0}\right) / \mathrm{d}$ with $\mathrm{h}_{0} / \mathrm{d}$ depending on the substrate nature. Such simple law of variation is explained by the fact that a substrate or a free surface does not change the dewetting temperature $T_{w}$ which remains equal to $T_{n+}$ whatever $\Delta$ h may be. Liquid film wets prefrozen layer and does not wet substrate above $T_{n+}$. A long isothermal annealing above $T_{g}$ leads, in all polymer examples, to the enthalpy of Phase 3, which can be hidden at high heating rate in the absence of annealing or formed above $\mathrm{T}_{\mathrm{g}}$ at low heating rate without annealing.

Thin films of various thicknesses are rinsed with solvents to obtain an ultrathin film deposited on substrates. Residual layer thickness $h_{r}$ depends on annealing temperature $T_{a}$ and is glass phase below $T_{g}$, submitted to melting and dewetting at $T_{g}$, and restored when prepared near $T_{m}$ as crystallized prefrozen layer above $T_{m}$ for film thickness weaker than $h_{c}=h_{r} / F \cong$ $\mathrm{h}_{\mathrm{r}} / 0.15$. Melting of residual layer is expected to occur at $\mathrm{T}_{\mathrm{g}}$ because Phase 3 is formed above $\mathrm{T}_{\mathrm{g}}$ in polymers and is hidden below $\mathrm{T}_{\mathrm{g}}$ in classical glasses.

The predicted existence of a melting temperature $T_{n+}=295 \mathrm{~K}$ of ice prefrozen layer in water is confirmed by various simulation studies already published by other authors.

The residual layer crystallizes by heating as prefrozen layer, disappearing at the melting temperature $\mathrm{T}_{\mathrm{n}+}$ of bulk Phase 3 because it has memorized the thermal history of Phase 3 before crystallization. Phase 3 , after crystallization, gives rise to a residual volume fraction $\mathrm{F} \cong 0.15$ 
of tiny crystals melting at $\mathrm{T}_{\mathrm{n}+}$. The formation of plastic crystals in $\mathrm{CCl}_{4}$ and ethanol is reexamined using this finding. Islands of Phase 3, being formed during undercooling above $\mathrm{T}_{\mathrm{g}}$, gives rise to a fraction of surviving crystals weaker than $F=0.15$ without phase transition at $\mathrm{T}_{\mathrm{n}+}$.

The adsorbed layer acts as a second substrate below $\mathrm{T}_{\mathrm{m}}$ and is the melted version of the prefrozen crystallized layer resulting from the first-order transition already observed at $T_{n+}$. Ultrathin films are divided in two distinct phases, each having its own $\mathrm{T}_{\mathrm{g}}$ : the first one is the dense layer of thickness $h_{r}$ in contact with the substrate and the second one has a thickness (h$\left.h_{r}\right)$.

Description of materials crystallization must be revised. A second melting temperature can exist above $\mathrm{T}_{\mathrm{m}}$. Various scenarios, depending on the presence of ordered Phase 3 or only islands of Phase 3 in the melt, must be envisaged between $T_{m}$ and $T_{n+}$. Absence of surviving crystals above $\mathrm{T}_{\mathrm{m}}$ leads to crystallization or amorphous phase after deep undercooling.

The highest melting temperature $T_{n+}$ of prefrozen layer of films having a thickness $h<$ $\mathrm{h}_{0}$ stays equal to that of bulk polymer after its thermal history at lower temperature and has for consequence that the relative variations of temperatures $\Delta \mathrm{T}_{\mathrm{n}+} / \mathrm{T}_{\mathrm{n}+\text { bulk }}, \Delta \mathrm{T}_{\mathrm{m}} / \mathrm{T}_{\mathrm{m}}$ bulk and of melting entropy $\Delta \mathrm{S}_{\mathrm{m}} / \mathrm{S}_{\mathrm{m}}$ (bulk) for $\mathrm{h}<\mathrm{h}_{0}$ are proportional to $\Delta \mathrm{T}_{\mathrm{g}} / \mathrm{T}_{\mathrm{g}}$ bulk.

Acknowledgments: The authors thank G. Vignaud and N. Delorme for a critical reading of our first manuscript.

\section{References}

1. J. K. Bal, T. Beuvier, A. B. Unni, E. A. Chavez Panduro, G. Vignaud, N. Delorme, M. S. Chabil, Y. Grohens, and A. Gibaud. Stability of polymer ultrathin films $(<7 \mathrm{~nm})$ made by a top-down approach. AC Nano. 2015, Vol. 9 (8), pp. 8184-8193.

2. A. Beena Unni, G. Vignaud, J.K. Bal, N. Delorme, T. Bouvier, S. Thomas, Y. Grohens, and A. Gibaud. Solvent assisted rinsing: Stability/instability of ultrathin polymer residual layer. Macromolecules. 2016, Vol. 49, pp. 1807-1815.

3. Aparma Beena Unni. Structuration and glass transition temperature of the adsorbed polymer layer :. https://tel.archives-ouvertes.fr/tel-01439328. [Online] 2017. Thesis . HAL Id: tel-01439328.

4. J. A. Forrest, K. Dalnoki-Veress, and J. R. Dutcher. Interface and chain confinement effects on the glass transition temperature of thin polymer films. Phys. Rev. E. 1997, Vol. 56 (5), p. 5705.

5. J. Ouyang, C-W Chu, C. R. Semanda, L. Ma, Y. Yang. Programmable polymer thin film and nonvolatile memory device. Nat. Mat. 2004, Vol. 3 (12), pp. 918-922.

6. V. K. Vendra, L. Wu, S. Krishnan. Nanotechnologies for the life sciences. s.I. : Wiley-VCH Verlag GmbhH \& Co, 2007.

7. X. Liu, P. X. Ma. Polymeric scaffolds for bone tissue engineering. Ann. Biomed. Eng. 2004, Vol. 32 (3), pp. 477-486.

8. Q. Huang, I. Yoon, J. Villanueva, K. Kim, D. Siburly. Quantitative mechanical analysis of thin compressible polymer monolayers on oxide surfaces. J. soft Matter. 2014, Vol. 10 (40), pp. 80018010.

9. M. J. Burroughs, S. Napolitano, D. Cangialosi, and R. D. Priestley. Direct Measurement of Glass Transition Temperature in Exposed and buried adsorbed polymer nanolayers. Macromolecules. 2016, Vol. 49, pp. 4647-4655.

10. R. S. Tate, D. S. Fryer, S. Pasqualini, M. F. Montague, J. J. de Pablo, and P. F. Nealey. Extraordinary elevation of the glass transition temperature of thin glass polymer fims grafted to silicon oxyde substrates. J. Chem. Phys. 2001, Vol. 115, pp. 9982-9990.

11. J. A. Forrest, K. Danoki-Veress, J. R. Stevens, and J. R. Dutcher. Effect of free surfaces on the glass transition temperature of thin polymer films. Phys. Rev. Lett. 1996, Vol. 77, pp. 2002-2005. 
12. M. Tariq, O. Dolynchuk, and T. Thurn-Albrecht. Effect of substrate interaction on thermodynamics of prefreezing. Macromolecules. 2019, Vol. 52, pp. 9140-9148.

13. A-K Löhmann, T. Henz, and T. Thurn-Albrecht. Direct observation of prefreezing at the interface melt-solid in polymer crystallization,. PNAS. 2014, Vol. 111, pp. 17368-17372.

14. A.-K. Flieger, M. Schultz, and T. Thurn-Albrecht. Interface-induced crystallization of polycaprolactone on graphite via first-order prewetting of the crystalline phase. Macromolecules. 2018, Vol. 51, pp. 189-194.

15. R. P. Sear. Continuity of the nucleation of bulk and surface phases. J. Chem. Phys. 2008, Vol. 129, p. 164510.

16. . Nucleation: Theory and applications to protein solutions and colloidal suspensions. J. Phys. Cond. Matter. 2007, Vol. 19, p. 0.33101.

17. M. Iwamatsu. Heterogeneous critical nucleation on a completely wettable substrate. J. Chem. Phys. 2011, Vol. 134, p. 234709.

18. M. Heni, H. Lowen. Surface freezing on patterned surfaces. Phys. Rev. Lett. 2000, Vol. 85 (17), pp. 3668-3671.

19. O. Dolynchuk, M. Tariq, and T. Thurn-Albrecht. Phenomenological theory of First-order prefreezing. Phys. Chem. Lett. 2019, Vol. 10, pp. 1942-1946.

20. R. F. Tournier and E. Beaugnon. Texturing by cooling a metallic melt in a magnetic field. Sci. Technol. Adv. Mater. 2009, Vol. 10, p. 014501.

21. Y. Yue. Experimental evidence for the existence of an ordered structure in a silicate liquid above its liquidus temperature. J. Non-Cryst. Sol. 2004, Vol. 345 \& 346, pp. 523-527.

22. A. Sharma, and R. Khanna. Pattern formation in unstable thin liquid films. Phys. Rev. Lett. 1998, Vol. 81 (16), pp. 3463-3466.

23. R. P. Wool. Twinkling fractal theory of the glass transition. J. Polymer Sci. Part B, Polym. Phys. 2008, Vol. 46, pp. 2765-2778.

24. R. P. Wool, A. Campanella. Twinkling fractal theory of the glass transition: rate dependence and time-temperature superposition. J. Polymer Sci. Part B Polym. Phys. 2009, Vol. 47, pp. 2578-2589.

25. J. F. Stanzione III, K. E. Strawhecker, R. P. Wool. Observing the twinkling nature of the glass transition. J. Non-cryst. Sol. 2011, Vol. 357, p. 311.

26. M. I. Ojovan. Ordering and structural changes at the glass-liquid transition. J. Non-Cryst. Sol. 2013, Vol. 382, p. 79.

27. M. I. Ojovan, K. P. Travis, and R. J. Hand. Thermodynamic parameters of bonds in in glassy materials from viscosity temperature relationships. J. Phys.: Cond. Matter. 2007, Vol. 19, p. 415107.

28. M. I. Ojovan, W.E. Lee. Connectivity and glass transition in disordered oxide systems. J. NonCryst. Sol. 2010, Vol. 356, pp. 2534-2540.

29. R. F. Tournier. Glass phase and other multiple liquid-to-liquid transitions resulting from two-liquid competition. Chem. Phys. Lett. 2016, Vol. 665, pp. 64-70.

30. R. F. Tournier. First-order transitions in glasses and melts induced by solid superclusters nucleated by homogeneous nucleation instead of surface melting. Chem. Phys. 2019, Vol. 524, pp. 40-54.

31. R. F. Tournier-. Homogeneous nucleation of phase transformations in supercooled water. Physica B. 2020, Vol. 579, p. 411895.

32. R. F. Tournier and M. Ojovan. Undercooled Phase Behind the Glass Phase with Superheated Medium-Range Order above Glass Transition Temperature. Physica B. 2020.

33. C. A. Angell, K. J. Rao,. Configurational excitations in condensed matter and the "bond lattice". Model for the liquid-glass transition. J. Chem. Phys. 1972, Vol. 57, pp. 470-481.

34. T. Iwashita, D. M. Micholson, and T. Egami. Elementary excitations and crossover phenomenonin liquids. Phys. Rev. Lett. 2013, Vol. 110, p. 205504.

35. M. I. Ojovan, D. V. Louzguine Luzgin. Revealing Structural Changes at Glass Transition via Radial Distribution Functions. 2020, Vol. 124, 3186-3194.

36. S. Wei, F. Yang, J. Bednarcik, I. Kaban, O. Shuleshova, A. Meyer \& R. Busch. Liquid-liquid transition in a strong bulk metallic glass-forming liquid. Nature Commun. 2013, Vol. 4, p. 2083. 
37. Y. He, J. Li, J. Wang, H. Kou, E. Beaugnon. Liquid-liquid structure transition and nucleation in undercooled Co-B eutectic alloys. Applied Physics A. 2017, Vol. 123, p. 391.

38. R. F. Tournier. Presence of intrinsic growth nuclei in overheated and undercooled liquid elements. Physica B. 2007, Vol. 392, pp. 79-91.

39. M. C. Righetti. Crystallization of polymers investigated by temperature-modulated DSC. Materials. 2017, Vol. 10, p. 442.

40. Varum, Ratta. Crystallization, morphology, thermal stability and adhesive properties of novel high performance semicrystalline polyimides. s.l. : Virginia Tech, 1999. Vol. Chapter 8. [14662]. http://hdl.handle.net/10919/27771.

41. M. Muthukumar. Communication: Theory of melt-memory in polymer crystallization. J. Chem. Phys. 2016, Vol. 145, p. 031105.

42. B. Wunderlich. Study of the change in specific heat of monomeric and polymeric glasses during the glass transition. J. Chem. Phys. 1960, Vol. 64 (8).

43. R. F. Tournier. Fragile-to-fragile liquid transition at Tg and stable-glass phase nucleation rate maximum at the Kauzmann temperature,. Physica B,. 2014, Vol. 454, pp. 253-271.

44. R. F Tournier. Thermodynamic origin of the vitreous transition. Materials. 2011, Vol. 4, pp. 869892.

45. D. Lin and S.J. Wang. Structural transitions of polyethylene studied by positron annihilation. 1992, Vol. 4, pp. 3331-3336.

46. M. Asada, N. Jiang, L. Sendogdular, P. Gin, Y. Wang, M. K. Endoh, T. Koga, M. Fukuto, D. Schultz and $\mathbf{M}$. Lee, X. Li, J. Wang, M. Kikuchi, and A.Takahara. Heterogeneous lamellar structures near the polymer/substrate interface,. Macromolecules. 2012, Vol. 45, pp. 7098-7106.

47. B. Azimi, N. Nourpanah, M. Rabica, S. Arbab. Poly (e-Caprolactone) fiber: an overview. J. Eng. Fib. Fab. 2014, Vol. 9 (3), pp. 74-90.

48. U. Gaur and B. Wunderlich. Heat capacity and otherthermodynamic properties of linear macromolecules; V. polystyrene. J. Phys. Chem. Ref. Data. 1982, Vol. 11 (2), pp. 313-325.

49. D. Cangialasi, V. M. Boucher, A. Alegria, and J. Colmenero. Direct evidence of two equilibrium mechanisms in glassy polymers. Phys. Rev. Lett. 2013, Vol. 111, p. 095701.

50. A. J. Pastor, B. G. Landes, P.J.Karjala. Thermal properties of syndiotactic polystyrene. Therm. Chim. Acta. 1991, Vol. 177, pp. 187-195.

51. N. Brun, P. Bourson, S. Margueron, M. Duc. Study of the thermal behavior of syndiotactic and atactic polystyrene by Raman spectroscopy. Jeep. 2011. DOI: 10.1051/jeep/201100004.

52. M. Y. Efremov, E. A. Olson, M. Zhang, Z. Zhang, and L. H. Allen. Glass transition in ultrathin polymer fims: calorimetric study. Phys. Rev. Lett. 2003, Vol. 91, p. 085703.

53. J. H. Kim, J. Jang, W.-C. Zin. Thickness dependence of the melting temperature of thin polymer films. Macrom. Rap: Comm. 2001, Vol. 22 (6), pp. 386-389.

54. Y. Wang, S. Ge, M. Rafailovitch, J. Sokolov, Y. Zou, H. Ade, J. Luning, A. Lustiger, and G. Maron. Crystallization in the thin and ultrathin films of poly(ethylene-vinyl acetate) and linear low-density polyethylene. Macromolecules. 2004, Vol. 37 (9), pp. 3319-3327.

55. T. Kajiyama, H. Hakabe, D. Kawaguchi, A. Takahara, K. Tanaka. Melting behavior of thin polyethylene films. J. Plastic film \& sheet. 2015, Vol. 31 (4), pp. 401-413.

56. S. Albert, Th. Bauer, M. Michl, G. Biroli, J.-P. Bouchaud, A. Loidl, P. Luckenheimer, R. Tourbot, C. Wiertel-Gasquet, F. Ladieu. Fifth-order susceptibility unveilqs growth of thermodynamic amorphous order in glass-formers. Science. 2016, Vol. 352, pp. 1308-1311.

57. M. I. Ojovan. Topological characteristics of bonds in $\mathrm{SiO} 2$ and $\mathrm{GeO}$. oxide systems at glass-liquid transition. J. Exp. Theor. Phys. 2006, Vol. 103 (5), pp. 819-829.

58. J. L. Keddie, R. A. L. Jones, and R. A. Cory. Glass transition in thin polymer films. Europhy. Lett. 1994, Vol. 27 (1), p. 59.

59. G. Vignaud, M. S. Chabil, J. K. Bal, N. Delorme, T. Beuvier and Y. Grohens, and A. Giraud. Densification and depression in glass transition temperature in polystyrene thin films. Langmuir. 2014, Vol. 30, pp. 11599-11608. 
60. F. D. Blum, E. N. Young, G. Smith, and O. C. Sitton. Thermal analysis of absorbed poly (methyl methacrylate) on silica. Langmuir. 2006, Vol. 22 (10), pp. 4741-4744.

61. C. Wang, Y. Yang, H. Fang. Recent advances on "ordered water monolatyer that does not completely wet water" at room temperature. Sci. Chin. Phys. Meca.\& Astr. 2014, Vol. 57 (5), pp. 802809.

62. D. Takaiwa, I. Atano, K. Koga, and H. Tanaka. Phase diagram of water in carbon nanotubes. PNAS. 2008, Vol. 105 (1), pp. 39-43.

63. M. Raju, A. van Duin. Phase transitions of ordered ice in graphene nanocapillaries and carbon nanotubes. Scientific Reports. 2018, Vol. 8, p. 3851.

64. G. X. Nie, J. Y. Huang, and J. P. Huang. Melting-freezing transition of monolayer water confined by phosphorene plates. J; Phys. Chem. B. 2016, Vol. 120, pp. 9011-9018.

65. J. F. G. Hicks, J. G. Hooley, and C. C. Stephenson. The heat capacity of carbon tetrachloride from 15 to $300 \mathrm{~K}$. the heats of transition and fusion. The entropy from thermal measurements compared with entropy from molecular data. J. Am. Chem. Soc. 1944, Vol. 66, pp. 1064-1067.

66. Y. Z. Chua, M. Tylinski, S. Tatsumi, M. D. Ediger, and C. Schick. Glass transition and stable glass formation of tetrachloromethane. J. Chem. Phys. 2016, Vol. 144, p. 244503.

67. Y. Koga, and J. A. Morrison. Polymorphism in solid CCl4. J. Chem. Phys. 1975, Vol. 62, p. 3359.

68. O. Haida, H. Suga, and S. Seki,. Calorimetric study of the glassy state. XII. Plural glass-transition phenomena of ethanol. J. Chem. Therm. 1977, Vol. 9, pp. 1133-1148. 